Article

\title{
Imaginaries of Road Transport Automation in Finnish Governance Culture-A Critical Discourse Analysis
}

\author{
Janne J. Olin * and Miloš N. Mladenović (D)
}

Citation: Olin, J.J.; Mladenović, M.N. Imaginaries of Road Transport Automation in Finnish Governance Culture-A Critical Discourse

Analysis. Sustainability 2022, 14, 1437. https: / /doi.org/10.3390/su14031437

Academic Editors: Gillian Harrison, Kate Pangbourne and

Caroline Mullen

Received: 30 November 2021

Accepted: 5 January 2022

Published: 27 January 2022

Publisher's Note: MDPI stays neutral with regard to jurisdictional claims in published maps and institutional affiliations.

Copyright: (C) 2022 by the authors. Licensee MDPI, Basel, Switzerland. This article is an open access article distributed under the terms and conditions of the Creative Commons Attribution (CC BY) license (https:// creativecommons.org/licenses/by/ $4.0 /)$.
Department of Built Environment, Aalto University, 02150 Espoo, Finland; milos.mladenovic@aalto.fi * Correspondence: janne.olin@aalto.fi

\begin{abstract}
As transport automation technology continues to emerge, there is a need to engage in the questions of its governing - to find a balance between unreflective enablement and rigid control. An increasing body of literature has begun to address the topic, but only a few studies have examined discourse and culture as central components of the related governance processes. This article aims to analyse the discourse surrounding self-driving vehicles in the Finnish context by drawing from the concept of sociotechnical imaginaries. The critical discourse analysis framework is applied to study a comprehensive set of documents published by Finnish national-level governmental bodies from 2013 to 2020. The analysis identifies four imagined ways of implementing self-driving vehicles into the Finnish transport system and a large set of mostly positive anticipated implications. Moreover, the analysis illustrates the transport automation imaginary's cultural and spatial detachment, most obvious in the lack of detail and the disconnection between the imagined implementations and the anticipated implications. The findings are convergent with findings from other governance contexts, where discourse has been largely characterised by an unjustified optimism and strong determinism related to the wedlock with the automobility regime. If left unaddressed, such lack of reflectivity will not just lead to a plethora of undesired implications for Finnish society at large but will also signify a failure in developing an adaptive governance culture needed to face challenges of the 21st century.
\end{abstract}

Keywords: transport governance; transport policy; imaginary; document analysis; automated vehicle; self-driving vehicle; emerging technology; mobility as a service; Finland

\section{Introduction}

The most recent wave of investments into the development of self-driving vehicles (SDVs) worldwide is bringing along hopes of better mobility but also urgent questions around uncertain societal implications and governance of innovation and technology [1-8]. The increasing number of pilot projects and semi-automated passenger cars on the market call for serious deliberation on the potential sociotechnical trajectories and associated societal implications.

SDVs are currently evoking the same problems that any societally significant emerging technology would [9]. More precisely, avoiding baneful lock-ins and transitioning out of currently unsustainable mobility systems requires that we acknowledge the valueladen nature of this technology [10] and the inevitable Collingridge dilemma related to the tradeoff between predicting its implications and steering development [11]. As is, the emergence of SDVs is mostly under the responsibility of actors focused on technical innovation, such as incumbent car companies and new entrants, often in the form of startups. Besides these actors, governmental bodies are also becoming more engaged in the development process. Although the latter receive significantly less attention, the role of governmental bodies cannot be understated, as they have historically had a decisive role in setting up sociotechnical trajectories for emerging technologies in general [12] and in the transport sector in particular [13]. 
Despite the fact that governmental bodies are often associated with publicly-known laws, policies, and responsibilities, they also uphold a culture of governance with certain values and meanings [14-17]. Thus, just as we need to understand the possible implications of this emerging technology, there is a need to understand the associated governance approaches. On the one hand, this understanding helps in addressing the classical problem of many hands, where power and responsibilities are distributed across complex actor-networks [18]. On the other hand, understanding the current governance approach for the technology helps in filling the institutional void [19] by developing knowledge, structures, and policy mechanisms. Ultimately, this becomes a question of high-quality policy design [20] that must strike a fine balance between unreflective enablement and rigid control [21].

Although a generalisation can be made that nearly all governments looking to implement SDVs are dealing with these problems, clearly there is no one-size-fits-all solution to solving them. Hence, we can already see diverging governance approaches worldwide. Regarding safety matters of SDVs, Japan and China have implemented preventative policies, Germany and Singapore have taken a control-oriented approach, whereas countries such as the US, the UK, and Australia have avoided strict measures [7]. Behind alternative approaches to governing SDVs, we can identify different motivations related to the expected national and supranational ends, such as economic development, national identity and survival, managing the climate crisis, and transitioning out of unsustainable economies $[9,22,23]$. Moreover, different countries have different governance processes and traditions as well as existing regulatory frameworks. For example, despite being closely related geographically and culturally, the formal decision making process and legislation design to enable public testing of SDVs has been notably different in Sweden and Norway [23]. Finland, on the other hand, was able to proceed to experiment with SDVs before its Nordic neighbours because of the coincidentally permissive legislation [9].

Echoing Marsden and Reardon [24], context matters for the study of transport governance. Thus, any analysis needs to recognise the significance of spatio-cultural aspects regarding the possibilities of transport automation and the development of related governance processes. At the very least, effectively addressing the questions of governance requires acknowledging the existence of the local governing institutions, the cultural and spatial landscape they inhabit, and their role in developing local automation pathways. The literature about SDV governance has so far provided valuable, internationally transferable findings [2,6,25], but this type of local specificity has been lacking.

Part of providing a more contextualised analysis is to further unpack how mobility futures are crafted, especially in the case of the institutional void of emerging technologies. Besides the increasing number of pilot projects [26] and the irresponsible market testing [27], self-driving futures are also being crafted in more shrouded ways. Operating within the institutional void, governmental bodies exercise future-crafting power through discourse, oftentimes written in their own publicly available and widely disseminated documents. These discourse-based visions play a role in transforming mobility culture by constructing imaginaries of desirable societies, some of which will eventually become stabilised enough to (re)direct decision making and reshape societies. Therefore, deeper governance analysis needs to focus on how imaginaries are constructed, articulated, interpreted, and mediated in official documents and how these practices relate to broader developments in sociotechnical regimes. Previous literature has already identified a set of such discourse-based sociotechnical imaginaries of transport automation [9,22,28-31]. However, while often successful in tapping into certain local specificities, the literature has, for the most part, settled on describing the characteristics and origins of the discourse, whereas the possible implications of the discourse are not contemplated as rigorously. Consequently, this branch of SDV literature might miss an important historical opportunity to intervene in possibly detrimental sociotechnical trajectories.

We place our study at the intersection of studies focusing on SDV governance and ones focusing on the discourse by incorporating elements from both. The scope of the 
study is on the most influential national-level governmental bodies of Finland. Finland is potentially an interesting critical case, as it is a nation that prides itself on being on the front lines of SDV development while at the same time being heavily car-dependant [32]. As such, we aim to offer meaningful critique both for SDVs as a supranational phenomenon and the Finnish transport governance regime. The analysis examines the discourse present in the official documents of Finnish national-level governmental bodies published during the period 2013-2020. More precisely, the research questions are the following:

1. What are the imagined uses of SDVs in future road passenger transport?

2. What are the assumed implications of road passenger transport automation?

3. What kind of rhetoric is used to convey these visions?

The outline of this article is as follows. The next section presents a summary review of the relevant literature in the domain of governance of SDV technology, clarifying the gap stated above. In the third section, we lay the groundwork for understanding the culture and discourse as we provide a brief look at the most essential governmental bodies and their predecessors responsible for national-level transport governance in Finland. Section four explains our methodology and analytical framework in closer detail. Section five presents the findings based on our discourse analysis of the selected governmental documents. The possible implications of the discourse and related sociocultural practices are contemplated in the final section of this work, drawing implications for the development of the governance approach and future research.

\section{Critical Literature on the Governance of Self-Driving Vehicle Technology}

Despite the constantly emerging real-world SDV applications, governments have mostly avoided stringent measures with the technology [7]. Policymakers have so far focused on enabling pilots, while countries and cities have increasingly incorporated SDVs into their plans and visions [33]. Simultaneously, a growing body of academic literature has begun to examine the questions of transport policy and governance concerning the uncertain aspects of the emerging technology (see, for example, $[1,3,6,7,23,25,33-43])$. This research has come to a few interconnected and troubling conclusions:

- Positive expectations of SDVs are found to be highly weighted over concerns;

- Governance actions are found to be lagging behind technological development processes;

- Innovation and policy processes related to SDVs are found to be insufficiently inclusive and democratic, as they are driven by economic prospects and the fear of missing out;

- $\quad$ Path dependance, laissez-faire governance, and vested interests are feared to lock countries deeper into the system of automobility through the widespread introduction of SDVs.

Although extensively basing its findings on discourse practices, such as literature reviews, interviews, and expert workshops, this branch of SDV literature has not heavily focused on discourse as a central part of governance processes. Studies drawing mainly from sociological traditions have recently begun to fill this gap.

Braun and Randell [28] argued how perhaps the main justification for pursuing automated mobility, i.e., the promise of traffic safety, has been artificially constructed on mistaken premises and made true by repetition. The constantly repeated fallacy that road violence is primarily a human quality and not an intrinsic feature of the automobility system has stabilised the SDV as an attractive solution to achieving road safety without system-level intervention. Moreover, SDVs are primarily understood as technological artefacts in the engineering-oriented discourse, whereas their social aspects are neglected, leading to a deterministic illusion of inevitable technological progress. This paradigm helps considerably in avoiding the conflicts between the optimistic visions and the implications related to the deeper lock-in to the automobility system.

Hopkins and Schwanen [44] provided a vivid example of how SAE's levels of automation, a widely adopted framework constructed by a very limited number of "experts", has 
already affected, and continues to affect, the technological trajectory of SDVs, possibly in an unfavourable way. Originally made to ease discussion about the degree of vehicle automation, the levels of automation have become the "de facto" industry standard that is referred to wherever SDVs are discussed. For its comprehensibility, the automation levels framework has opened the door to the discussion for non-experts, but simultaneously it can be considered as oversimplified, deterministic, and somewhat deceiving. The framework presents technological innovation as a linear process, lacks cultural and spatial sensitivity, and reproduces discourse that solidifies the dominance of the passenger car in the mobility system. Considering that the levels of automation have been featured likely in hundreds of policy documents internationally, it is easy to agree with the authors' conclusion that the framework has likely narrowed down deliberation about the various potential implementations of SDVs. In a similar vein, Martin [30] highlighted how incumbent actors in the private sector use image-based discourse conventions to stabilise the changing regime to their benefit, limiting the scope of deliberation to technological substitution within a business-as-usual world based on private automobility.

Adding to these approaches, several authors have examined the governance of transport automation through a nation-specific lens. Graf and Sonnberger [29] illustrate how in the German stakeholder discourse the public is portrayed simultaneously as irrationally fearful and as rational decision-makers (i.e., homo economicus) depending on the context. Uncertainties and possible negative implications of transport automation are identified by the stakeholders as sources of fear that distract otherwise rational decision-makers. Consequently, communicating the benefits of automation, as perceived by the stakeholders, is expected to reduce these fears and enhance acceptance. The discourse stresses the importance of participation in generating acceptance, but simultaneously the public is reduced to merely a recipient of the supposedly correct information instead of an active co-creator of the emerging technology. Tennant et al. [31] reported convergent findings to Graf and Sonnberger from a UK corpus analysis: the public is presented as deficient, ignorant, and fearful of that which they do not properly understand. In addition, the authors illustrate how a limited, selective, and relatively homogenous group of stakeholders seek to construct a narrative, where self-driving technologies are presented as inevitable and desirable.

Taking a more culturally sensitive approach, Haugland [22] showed how self-driving technologies are framed in Norwegian political discourse as a contributor to a national "green shift" as well as an important economic prospect, while little focus is paid on actual transport system issues and implementability. Similarly, examining SDVs from Nordic, Rhinelandic, and British Isles governance traditions, Mladenović et al. [9] showed how technodeterministic discourse is mobilised to depict SDVs as vital for economic growth, which in turn is connected to the rhetoric of national identity, survival, and position in the global economy.

\section{Overview of Finnish Transport Governance}

This section describes the formal constellation of main actors on the national level and summarises the recent literature illuminating certain aspects of the governance culture. Before proceeding, we must recognise the complexity of transport governance as an activity that transcends nearly all parts of social life, an activity that is to a great extent carried out in informal and opaque interactions between layered and constantly altering actors from private persons to municipalities, governmental actors, and transnational tech companies [45]. The network of actors could reasonably be extended to include even inanimate objects [46]. Therefore, providing a comprehensive description of the Finnish transport governance actors and activities in a single section would be extremely difficult and is not within the boundaries of this study. Here, we also note that Finnish transport governance has received relatively little attention in academic literature compared even to other Nordic countries [47], although in recent years, the emergence of the Mobility as a Service concept (MaaS) has generated a small surge in this literature branch. The scarcity of studies addressing historical, cultural, and operational aspects of Finnish transport gov- 
ernance complicates grasping the roles and responsibilities of the relevant actors, especially regarding how they operate informally beyond their legally determined core functions. Nevertheless, attempting to shed some light on the matter is not in vain.

\subsection{Actors and Temporal Change}

The foremost authority in Finnish transport governance is the Ministry of Transport and Communications (MTC) led by the Minister of Transport, a person selected from one of the multiple parties often forming a coalition in the Finnish democratic system. The Finnish law dictates the MTC's core functions. These include fulfilling a set of organisational goals, the responsibility of preparing laws in the Ministry's administrative area, handling matters concerning the European Union and international cooperation, as well as managing activities related to research, analysis, evaluation, and future anticipation [48]. The administrative sector of the MTC currently consists of two agencies, one institute, and several state-owned companies, many of which have experienced considerable organisational changes in recent history, with the latest taking place at the beginning of 2019. Currently, the most essential transport governance organisations under the MTC are:

- The Finnish Transport and Communications Agency (Traficom), which engages in transport system development, digitalisation, and safety matters by issuing permits and participating in experimentation, for example, self-driving shuttle pilots. The agency was formed by merging three former agencies: the Finnish Transport Safety Agency (Trafi), the Finnish Communications Regulatory Authority (FCRA), and parts of the Finnish Transport Agency (FTA);

- The Finnish Transport Infrastructure Agency (Väylä), which was formed from parts of the FTA. The agency is responsible for the maintenance of Finland's road, rail, and waterway systems;

- Traffic Management Company Fintraffic Ltd., Helsinki, Finland (Fintraffic), which is a state-owned company that participates in the control and management of traffic on the land, in the air, and at sea. The company also seeks to advance the creation of new traffic and smart mobility solutions by providing traffic information to its customers.

Although the MTC is superficially the leading national-level organisation in terms of transport matters, the responsibilities and power relations are far more nebulous in practice. Operating parallel to the MTC and taking part in the national-level transport governance is the Ministry of Economic Affairs and Employment (MEE). Like the MTC, the MEE participates in policymaking and law preparation in its administrative sector, which includes the operating environment of Finnish entrepreneurship and innovation, labour market, and regional development in the global economy. In recent years, the MEE has increasingly engaged in transport affairs, possibly due to the public introduction of several innovations that are expected to bear significant economic impacts soon, with MaaS and transport automation perhaps being the most essential ones. Similarly to the MTC, the MEE also has several agencies in its purview. In terms of transport policy, the most notable of these agencies has been the Finnish Funding Agency for Technology and Innovation (TEKES), which was merged with Finpro Oy to form Business Finland in 2018. Although the agency does not bear any direct responsibilities regarding policymaking, TEKES has participated in the discourse by publishing reports and overviews related to Finnish innovation activities.

Besides these two ministries, also the Ministries of Finance (MF), Environment (ME), and Education and Culture (MEC) are involved in transport governance. The MF is involved, for example, in the taxation of transport, the ME in land use, housing, and transport agreements that are made between the State and the five largest urban regions, and the MEC in related education matters and transport aspects of tourism. Finally, the last governmental body identified as a key actor on the national level is the Committee for the Future (CFF). The CFF is an established, standing committee that consists of 17 Members of the Parliament, including members of parties that are not in the ruling coalition. Partly engaging in similar activities as the Ministries, the Committee serves as a think tank for 
futures, science, and technology policy in Finland. In addition, the CFF is a member of the European network of parliamentary technology assessment.

\subsection{Some Aspects of the Governance Culture}

As Finland is a multi-party Nordic democracy, the network described above also inevitably serves as an arena for political, value-based struggle, which is visible, for example, in the altering agendas of the actors. The existing research has characterised the governance regime of the 2000s as determined to advance innovation, economy-centric, constantly changing, and somewhat hindered by bureaucracy. Regarding the governance culture and its underlying values and norms, there is no exhaustive analysis, but several studies have touched on the subject.

Notable policy studies by Tuominen and Himanen [49] and Kivimaa and Virkamäki [50] presented a relatively broad range of transport policies, policy themes, and policy problems on the agenda of the governmental bodies related to innovation, economy, regional and urban development, health, social sustainability, and environment. Omitting the extent to which the mentioned problems have been addressed with effective policy measures, it could be said that the governmental bodies are conscious of a wide range of salient transport issues. Leviäkangas [51], examining the digitalisation of the Finnish transport sector, concluded that throughout the recent cabinets, there has been a strong will to advance the digitalisation of transport in Finland. The approach that the governmental bodies have taken can be described, according to Leviäkangas, as "rational, but somewhat adaptation-oriented", meaning that the digitalisation processes are foremost driven by the private sector. It is also suggested that social aspects of transport sector digitalisation are not addressed rigorously in transport governance, because the sector as a whole is not well-presented in the governmental agenda, and the central agencies' views on the matter are very techno-economic. Affirmation for the existence of the supposed techno-economic orientation at the expense of social consciousness, concerning not only the digitalisation but also the general development of the transport system, can be found, for example, in studies by Kivimaa and Virkamäki [50], Mladenović et al. [9], and Pangbourne et al. [52]. According to Upham et al. [53], as a consequence of path dependance stemming from strong historical economic commitment to private motoring, policy measures targeted at the mitigation of transport-related problems typically fall into the category of technological substitution (e.g., more environmentally friendly fuels and vehicles) instead of social innovation (e.g., demand management, promotion of sustainable modes such as public transport and cycling). The claim is hard to question, as the authors bring up quotes such as the following from key political strategies.

"The development of technology and innovation makes new methods and practices available to us on almost a daily basis, and consequently, we should not attempt to solve tomorrow's problems with today's tools." (p. 16)

The private-sector-driven innovation activities, on the other hand, seem to stem from a very distinct notion in the Finnish regime that the role of the private sector is to innovate, whereas the role of public actors is to enable innovation by providing convenient operating conditions for companies [52,54]. In expert interviews carried out by Kivimaa and Rogge [55], this paradigm of enablement is partly attributed to recent institutional changes, especially ones that took place in the administrative sector of the MTC in the early 2010s when aviation, road, rail, and marine transport agencies were merged into a single agency, Trafi (which was later merged to form Traficom). However, as explained, the regime can hardly be described as homogenous, and contradictory views on innovation can be found. Some studies have highlighted the public sector's eagerness to engage in and even lead the development of MaaS to ensure favourable outcomes for society and the environment $[54,56]$. 


\section{Methodology}

\subsection{Analytical Framework}

We base our analytical framework on the concept of sociotechnical imaginaries. Defined by Jasanoff and Kim, these are "collectively held, institutionally stabilized, and publicly performed visions of desirable futures, animated by shared understandings of forms of social life and social order attainable through, and supportive of, advances in science and technology" [12,57]. Sociotechnical imaginaries can stem from organisations of various characteristics as well as individuals. However, only when a vision becomes collectively enough accepted-although there may still be competing visions-does it become an imaginary. What visions become collectively accepted and eventually start directing decisionmaking can be regarded as an exercise of power [57]. As we illustrate later, transport automation is indeed an imaginary collectively held and consciously reinforced by multiple governmental bodies in Finland, even though, or perhaps just because, it lacks a stabilised meaning. In other words, transport automation is an interpretatively flexible concept [58], which makes it, through proper utilisation of discourse practices by actors of power, both easily desirable and resilient against deeper scrutiny. In this study, we do not evaluate whether a particular vision is collectively held or institutionally stabilised enough to be considered a proper "imaginary". Instead, we refer to all imagined forms of transport automation and the whole phenomenon as imaginaries.

Operationalisation of the sociotechnical imaginary concept is conducted by applying critical discourse analysis (CDA) [59] on the document sample presented in the next section. Our approach follows Fairclough's three-dimensional model of discourse [59] (p. 98) in principle, with the exception of starting from the level of discursive practices instead of textual practices. The discursive practices are understood here as discourse conventions used in the documents. The second part of our analysis is conducted on the level of textual practices, where we examine the interpretative content of the documents that the authors seek to communicate, i.e., the imaginaries. The third part of the analysis is our attempt to connect the discourse to certain sociocultural practices in the governance regime, and, by doing so, provide a deeper understanding of the Finnish governance culture regarding transport automation and transport system futures.

\subsection{Sampling}

The document sample (Table 1) consists of 34 documents of various types that were identified by scanning through the archives of the current and defunct governmental bodies presented in the background section. All documents published between the years 2011 and 2020 were superficially examined by glancing through the titles and abstracts. After the initial search, the chosen documents were skim-read, and the irrelevant documents were excluded leading to the final sample. The final inclusion criterion was that a document showed deliberation about transport automation beyond simply mentioning the phenomenon. Relevant documents were found from the archives of the following governmental bodies: the Ministry of Transport and Communications (MTC), the Ministry of Economic Affairs and Employment (MEE), the Finnish Transport and Communications Agency (Traficom), the Finnish Transport Agency (FTA), the Finnish Transport Safety Agency (Trafi), the Finnish Funding Agency for Technology and Innovation (TEKES), and the Committee for the Future (CFF). 
Table 1. The document sample used in the analysis.

\begin{tabular}{|c|c|c|}
\hline Publisher & Year & Title \\
\hline MTC & 2020 & Road map for fossil-free transport-Working group final report [60] \\
\hline MTC & 2020 & $\begin{array}{l}\begin{array}{l}\text { Road map for fossil-free transport-Decision in principle by the Finnish Government to reduce greenhouse gas emissions } \\
\text { of homeland transport * (draft) [61] }\end{array}\end{array}$ \\
\hline MTC & 2020 & Transport automation legislation and key policy measure plan * (draft) [62] \\
\hline MTC & 2019 & National Transport System Plan Impact Assessment Programme [63] \\
\hline MTC & 2018 & $\begin{array}{l}\text { Well-being and sustainable growth with well-functioning networks, services and information-Futures review by the } \\
\text { Ministry of Transport and Communications [64] }\end{array}$ \\
\hline MTC & 2018 & $\begin{array}{l}\text { Carbon-free transport by 2045-Paths to an emission-free future, interim report by the Transport Climate Policy working } \\
\text { group [65] }\end{array}$ \\
\hline MTC & 2018 & Action programme for carbon-free transport 2045 Final report by the Transport Climate Policy working group [66] \\
\hline MTC & 2018 & Analysis of the data and development needs of automated driving [67] \\
\hline MTC & 2017 & A roadmap for developing automation and robotics in transport sector 2017-2019 [68] \\
\hline MTC & 2017 & Making digital transport and communication services accessible. Action Programme 2017-2021 [69] \\
\hline MTC & 2017 & Transport and Communications Architecture 2030 and 2050 [70] \\
\hline MTC & 2017 & $\begin{array}{c}\text { Better transport infrastructure-More efficient transport services. Report on the business development of the transport } \\
\text { network: Transport Network Company [71] }\end{array}$ \\
\hline MTC & 2016 & Background reports on robotics [72] \\
\hline MTC & 2016 & Traffic safety from knowledge-Decision in principle by the Finnish Government to enhance road safety * [73] \\
\hline MTC & 2015 & Robots on land, in water and in the air-Promoting intelligent automation in transport services [74] \\
\hline MTC & 2014 & Our road to the future. Futures review on road safety [75] \\
\hline MTC & 2014 & Smart City—Overview of smart services and possibilities [76] \\
\hline MTC & 2013 & Fair and Intelligent Transport—Working Group Final Report [77] \\
\hline MEE & 2020 & $\begin{array}{l}\text { Transport sector indicators and situational picture. Proposals for growth programme assessment and for monitoring the } \\
\text { sector's development [78] }\end{array}$ \\
\hline MEE & 2019 & Leading the way into the age of artificial intelligence-Final report of Finland's Artificial Intelligence Programme 2019 [79] \\
\hline MEE & 2018 & Work in the age of artificial intelligence: Four perspectives on the economy, employment, skills and ethics [80] \\
\hline MEE & 2018 & National Growth Programme for Transport Sector 2018-2022 [81] \\
\hline MEE & 2017 & $\begin{array}{l}\text { Finland's Age of Artificial Intelligence-Turning Finland into a leading country in the application of artificial intelligence } \\
\text { [82] }\end{array}$ \\
\hline MEE & 2017 & Government report on the National Energy and Climate Strategy 2030 [83] \\
\hline Traficom & 2020 & From driver support systems to automation [84] \\
\hline Traficom & 2020 & The current state of the transport system and the changes in its operating environment [85] \\
\hline Traficom & 2019 & How safe must automated cars be? [86] \\
\hline Traficom & 2019 & Preliminary report on the accessibility of automated road vehicles and transport services [87] \\
\hline Traficom & 2019 & The impact of automated transport on the role, operations and costs of road operators and authorities in Finland [88] \\
\hline Trafi & 2016 & The state of transport 2030 [89] \\
\hline Trafi & 2015 & The effects of increased automation in road transport ${ }^{*}[90]$ \\
\hline CFF & 2018 & Societal transformation 2018-2037-100 anticipated radical technologies, 20 regimes, case Finland [91] \\
\hline FTA & 2016 & Road transport automation road map and action plan 2016-2020 [92] \\
\hline TEKES & 2014 & Innovation policy options for sustainability transitions in Finnish Transport [93] \\
\hline
\end{tabular}

* Unofficial translation of the title from Finnish.

\subsection{Document Analysis}

Our approach to studying the documents involves broader thematic analysis as well as detailed content analysis. On the level of discursive practices, we seek to roughly identify the document type by examining the content. Moreover, we examine the different discourse conventions applied in the text, such as the stylistic and rhetorical devices as well as the author's "voice" in general. This is done to better understand the roles that the multiple organisations take in the discourse and their motives. 
The second level of analysis, focusing on the textual practices, is executed by coding sentences with ATLAS.ti software. The coding scheme is based on identifying two principal components of the automation imaginary: implementations and their implications. From each document, we seek to distinguish the imagined ways of implementing SDV technologies into the Finnish transport system. This is done by identifying the suggested area of implementation, for example, private motoring or the public transport system. Additionally, we try to identify more specific details that characterise the implementations: vehicle types, operational design domains, and service designs. Then, we seek to identify the anticipated implications that are associated with each implementation. The implications are coded by examining the expected change in a given variable: an increase in the variable $(+)$, decrease in the variable $(-)$, neutral effect on the variable $(\mathrm{N})$, and uncertain effect on the variable (U). In case there is no apparent connection between an implementation and an implication, they are coded separately. If an implication is conditional on other implications or the in-text presentation is otherwise more complex, the implication is coded so that the chain of causality is as clear as possible. For further analysis, by interpreting the context and assumed voice of the author, the anticipated implications are also coded according to how desirable the authors perceive them: positive, negative, neutral, or uncertain. The following sentence illustrates the primary coding protocol:

"Shared automated vehicles (implementation) are likely to increase (increase in the variable) the efficiency of the transport system (variable)."

On the third level, sociocultural practices, we rely on inductive discourse coding to identify broader themes within the documents. As sociotechnical imaginaries' success is dependant on how they fit into the world as is [57], we are particularly interested in how the imaginaries are grounded into the transforming mobility culture and the Finnish transport governance regime. Pivotal topics of inquiry here include how the governmental bodies seek to realise their visions as well as the existing sociocultural realities that promote or hinder the realisation of the imaginaries.

\section{Findings}

\subsection{Discursive Practices}

The sample of documents consists of publications of various types from multiple authors in multiple organisations, while sometimes the authors come from outside the governmental organisations. We identify four broader document classes from the sample: policy documents, visions, studies, and decisions in principle. The document classes are a result of a rough categorisation, and there is much overlap between these classes. For example, policy documents tend to have many vision-like elements embedded in them. In our classification, policy documents include strategies, policy programmes, as well as reports with a strong emphasis on providing insight about possible policy measures. Studies include the various types of documents that mainly seek to generate or gather knowledge by different methodologies. Vision class includes documents that focus on depicting possible futures. In the Finnish governance system, a decision in principle is a specific document type, a political statement, that guides the state administration in the preparation of matters by providing broad outlines for future policy.

Figure 1 illustrates the document types that each organisation has published. The MTC has so far engaged with transport automation matters most frequently and by using the most diverse approaches. In contrast, nearly all documents by the MEE fall into the category of policy, and the organisations under the MTC have participated in the written discourse mostly by conducting studies about the phenomenon. As the sample of organisations and authors is diverse, the applied discursive practices also differ considerably within the various document classes. Here too, the MTC has used the most diverse practices. Across the various types of documents, depending on the subject at hand, the MTC articulates multiple discourse conventions, effortlessly shifting from being a visionary or a storyteller to being a political servant and many things in between. This plasticity can be observed by examining the voices of three authors in parallel: 


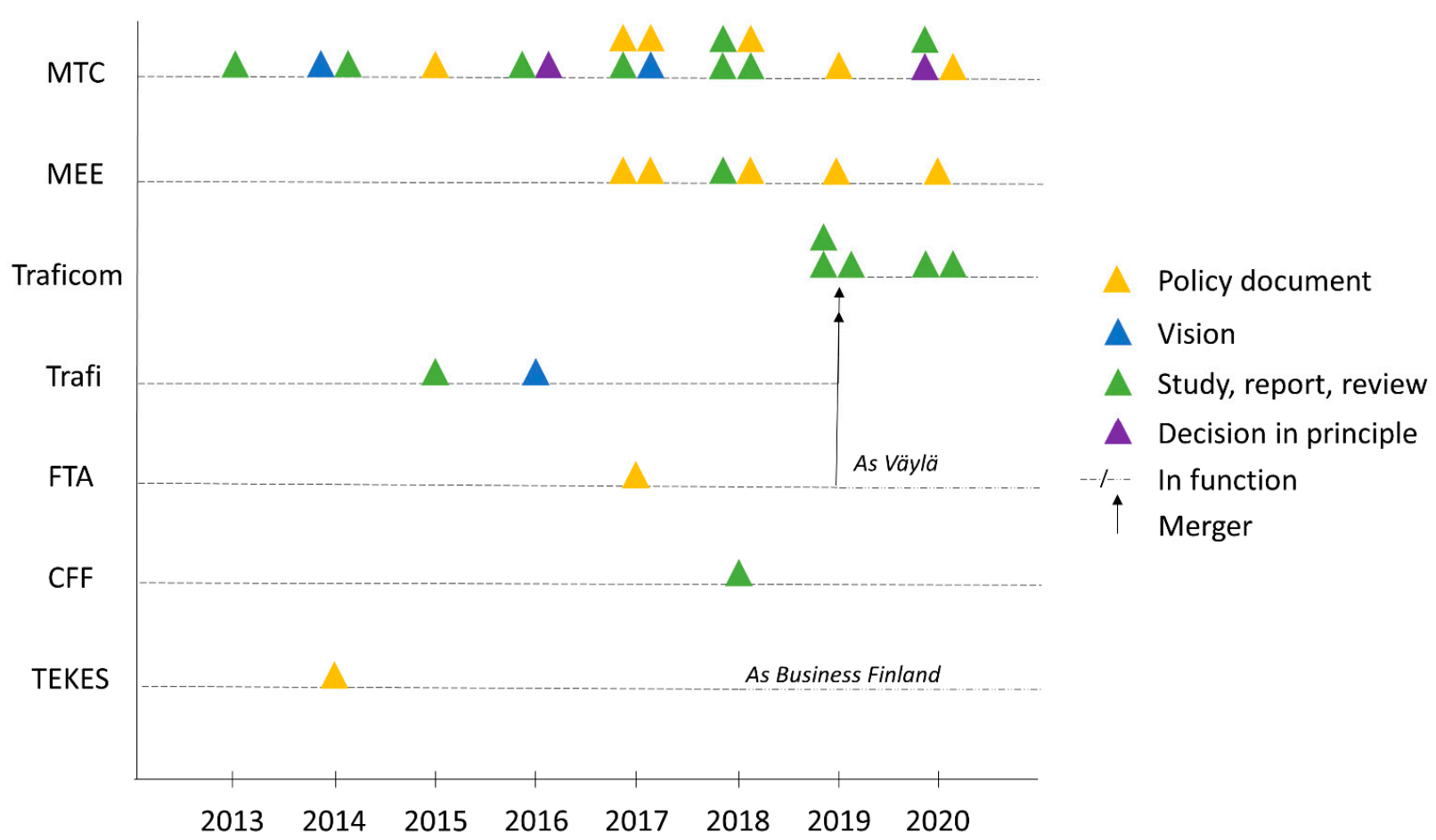

Figure 1. The document sample classification over time and per actor.

"The bus arrives at the bus terminal of the metro station... This time automation was noticeable only due to the absence of "good morning" from the driver. Sometimes in the evening this bus has been a little restless, s/he recalls." [67] (p. 11)

"Or how does a traffic junction in, for example, Shanghai sound like where hundreds of robotic scooters cross each other's driving lines without stopping, automatically dodging each other? Maybe the package will soon be delivered to your door by a quadrocopter based on a courier car that has driven to the district." [76] (p. 11)

"Incorporating an experimentation culture into traditional structures is a goal of the government program and a vital condition for our development and success." [68] (p. 2)

While it is important to acknowledge that the actors participate in the discourse on multiple levels and by taking different roles, the practices differ so greatly within the sample that listing them all would not be meaningful. Considering that these documents are conscious projections of the organisations' values and visions, as future depictions tend to be [94], it is more useful to try to grasp the interconnecting motivations that penetrate the sample. The task is not hard, as the organisations are quite explicit about their goals. Most notably, the MTC and its agencies do not take a neutral standpoint to transport automation but position themselves as enablers and promotors. Consequently, many, if not all, documents by these parties seem to begin from the premise that transport automation is unquestionably desirable, while some go even as far as to state that it is inevitable.

"The aim of the Ministry of Transport and Communications and its administrative agencies is to enable and promote the development of transport automation. Therefore, the purpose of the roadmap is to be as permissive and experiment-promoting as possible, while taking into account the safety of the transport system." [68] (p. 2)

"Anything that can reasonably be automated, will be-in transport as well as more generally in society." [74] (p. 40) 


\subsection{Textual Practices}

\subsubsection{Imagined Implementations of Self-Driving Vehicles}

In total, 22 out of the 34 documents explicitly discuss alternative SDV implementations. The four distinguishable implementations, which appear repeatedly in the analysed documents, are summarised in Table 2. Automated private motoring can be considered as the most stabilised imaginary, as it is mentioned in 18 out of those 22 documents (82\%). The second most common is the vehicle or ridesharing service, often referred to as a robot taxi service $(59 \%)$, followed by public transport feeder service $(50 \%)$ and public transport in general $(41 \%)$.

Table 2. The imagined implementations of SDVs identified from the analysed documents.

\begin{tabular}{|c|c|c|c|c|}
\hline & Private Motoring & Robot Taxi & $\begin{array}{c}\text { Public Transport Feeder } \\
\text { Service }\end{array}$ & $\begin{array}{c}\text { General Public } \\
\text { Transport }\end{array}$ \\
\hline Vehicle & $\begin{array}{l}\text { Connected, cooperative, and } \\
\text { automated passenger car. }\end{array}$ & $\begin{array}{l}\text { The image of a highly automated } \\
\text { passenger car is often invoked [87] } \\
\text { (p. 16), [88] (p. 46), but the concept is } \\
\text { also mixed with self-driving shuttles } \\
\text { [88] (p. 59) and remote control [85] } \\
\text { (p. 106). }\end{array}$ & $\begin{array}{l}\text { Automated low-capacity } \\
\text { shuttle with a possibility for } \\
\text { remote control. }\end{array}$ & $\begin{array}{l}\text { Automated bus } \\
\text { [85] (p. 106); } \\
\text { [74] (p. 11). }\end{array}$ \\
\hline $\begin{array}{c}\text { Service } \\
\text { characteristics }\end{array}$ & $\begin{array}{l}\text { Generally, the private } \\
\text { motoring imaginary resembles } \\
\text { the status quo in terms of } \\
\text { vehicle ownership, but it is } \\
\text { also, less frequently, connected } \\
\text { to the prospect of mobility } \\
\text { service bundles [77] (p. 8). }\end{array}$ & $\begin{array}{l}\text { The imaginary draws from the notion } \\
\text { of seamless door-to-door mobility and } \\
\text { servitisation of transport. Sometimes } \\
\text { robot taxis are imagined as a part of } \\
\text { the public transport system [66] (p. 65); } \\
\text { [85] (p. 106), sometimes as a more } \\
\text { conventional taxi service [87] (p. 14); } \\
\text { [88] (p. 27), sometimes they are left } \\
\text { completely undefined [62]. The } \\
\text { possibility of ride-sharing is also } \\
\text { mentioned, but generally, the } \\
\text { expectation seems to be that only } \\
\text { vehicles are shared [87] (p. 28). }\end{array}$ & $\begin{array}{l}\text { The shuttles are mostly } \\
\text { imagined as a part of the } \\
\text { public transport system, but } \\
\text { the concept is also mixed with } \\
\text { robot taxis, and even the } \\
\text { possibility of personal rapid } \\
\text { transit is mentioned [88] } \\
\text { (p. 59). }\end{array}$ & $\mathrm{N} / \mathrm{A}$ \\
\hline $\begin{array}{l}\text { Operational } \\
\text { design } \\
\text { domain }\end{array}$ & $\begin{array}{l}\text { The imagined implementation } \\
\text { process starts from limited, } \\
\text { relatively simple sections of } \\
\text { the road network, such as } \\
\text { highways, and eventually } \\
\text { expands as wide as possible } \\
\text { [62] (p. 19-20). }\end{array}$ & $\begin{array}{c}\text { Robot taxis are expected to eventually } \\
\text { operate flexibly on the whole road } \\
\text { network [87] (p. 16). }\end{array}$ & $\begin{array}{l}\text { Mostly associated with small, } \\
\text { definite areas or short, fixed } \\
\text { routes that support a higher } \\
\text { capacity public transport } \\
\text { connection. Examples include } \\
\text { urban [81] (p. 31); [67] (p. 11), } \\
\text { suburban and semi-rural areas } \\
\text { [74] (p. 16), and areas such as } \\
\text { hospitals and campuses [88] } \\
\text { (p. 16). }\end{array}$ & $\mathrm{N} / \mathrm{A}$ \\
\hline
\end{tabular}

It is often mentioned in the documents that transport automation makes a multitude of new services possible, yet it is rarely elaborated with more than a few sentences what these services could be. 12 out of the 34 documents do not mention any specific implementations, and the discussion in the other documents is, for the most part, heavily overgeneralised. In fact, implications, described in more detail in the following section, are repeatedly attributed simply to "transport automation" without making a distinction between the various implementations. The implementations are not deliberated with equal effort or specificity either, but even the most detailed depictions are quite disconnected from any local realities. Consequently, understanding what these interpretations of the larger transport automation imaginary mean in a practical sense for the Finnish transport system is difficult.

The most often mentioned implementation, private motoring, is also the most detailed one of the four. Automation is expected to take shape in the form of privately owned vehicles resembling the status quo. The development pathway is imagined as incremental in a technological and a spatial sense: manufacturers will incorporate more and more advanced driving assistance systems into their vehicles while operational design domains will increase in size. The feeder service one is relatively well explained as well. Especially 
in the early stages, automation is expected to be utilised in short-range feeder connections to the existing public transport system. Apart from these two, the authors do not discuss the possible implementations in detail. Excluding the feeder service, public transport is barely mentioned except by name, while grasping even the outlines of the imagined robot taxi service requires interpreting an incoherent story told across multiple documents.

It is inferable that robot taxis are expected to serve as a replacement for privately owned passenger cars, although they may resemble passenger cars and co-exist with them. The parting from conventional automobility then comes from the service dimension. In some documents, this imaginary withholds the notion that people will share rides (e.g., [88]), but more commonly vehicle sharing is implied. Whether it is the rides or the vehicles that are shared in the service, the imaginary seems to draw from the broader discussion about the end of car ownership as well as the servitisation of transport (Lanamäki, 2021; Plepys et al., 2015). The MaaS concept, which in itself lacks a stabilised meaning as shown by Mladenović and Haavisto [54], is often seen as synergistic with robot taxis, and in general with transport automation, mainly due to its presumed ability to nudge people into giving up personal vehicles by integrating various modes of transport conveniently into one mobility palette $[62,65,77,88]$. Vice versa, automation is expected to support MaaS services by enabling a more efficient allocation of resources, i.e., the vehicle fleet [88]. However, virtually no details of robot taxis or service bundling, besides the presumed positive implications, are seriously contemplated in the documents.

The reasons for the lack of detail and overgeneralised discourse seem to be manifold. The first reason could simply be the lack of knowledge at a specific point in time. As transport automation has truly taken to the streets as late as the 2010s, the Finnish governmental bodies have not previously engaged in serious deliberation about its various possible forms and their implications. However, the number of documents clearly illustrates that this deliberation has now been continuous and relatively extensive for a while; thus, the lack of knowledge does not apply to most of the documents.

The second reason is possibly linked with the path dependance within the prevailing sociotechnical regime based on automobility $[95,96]$. The document coding reveals that automation is not as much associated with novel positive effects as it is with easing or removing negative effects of the passenger car while maintaining the benefits. The imaginary of transport automation for Finland - a heavily car-dependant country-then becomes a one-for-one replacement of the passenger car. For some authors, this mental image seems to be so dominant that they effortlessly dismiss all other possible implementations or place very little emphasis on them. When discussing the effects of "transport automation", they are, in fact, discussing automated passenger cars. In other words, the authors assume that the main benefits of transport automation are almost exclusively connected to private motoring, which is visible from arguments such as the following:

"The Finnish car stock is one of the oldest in Europe, and its rate of renewal is slow. The average age of cars used on the roads in Finland at the end of 2014 was 11.4 years, while the corresponding average age in the entire EU area is some 8 years. Consequently, Finland will be one of the last countries to see the benefits of automation realised." [74] (p. 16)

The third possible reason for abstaining to discuss alternative implementations in detail is that the authors may choose to maintain comfortable interpretative flexibility in their writing. Thus, despite directly contributing to the creation of a technological trajectory, the authors can defend their superficially neutral stance by casting the responsibility of local implementations on other actors or by appealing to the uncertain aspects of the emerging technology. The approach is visible from most of the documents, as they rarely depict visions grounded to local realities and instead reiterate externally originated and relatively vague imaginaries, such as the SAE's levels of automation [44]. Another good example is the robot taxi service, which has become increasingly stabilised in recent documents as well as in the academic discourse [97-99]. By using the term, without ever properly clarifying how robot taxis would operate in Finland, the authors effectively bridge the national and 
supranational discourses while maintaining comfortable ambiguity in their vision-crafting work. This externally validated concept is strong enough to create positive mental images and simultaneously difficult to scrutinise, as the authors never discuss what robot taxis would mean locally. The most noticeable example of such rhetoric comes from a recent policy programme draft that lists "starting the robot taxi service production" as a goal for the years 2025-2030 without providing any explanation about the nature of the service [62] (p. 20).

\subsubsection{Anticipated Implications}

Figure 2 and Table S1 depict the 169 anticipated implications that were identified from the documents. We note here that the number of documents in which an implication is mentioned does not definitively indicate the importance that the governmental bodies place on said implication. For example, the usability of automated vehicles is seldom discussed in the documents, but one document in the sample specifically addresses the question. Nevertheless, the analysis gives us a good idea of the main benefits and threats that the governmental bodies associate with transport automation.

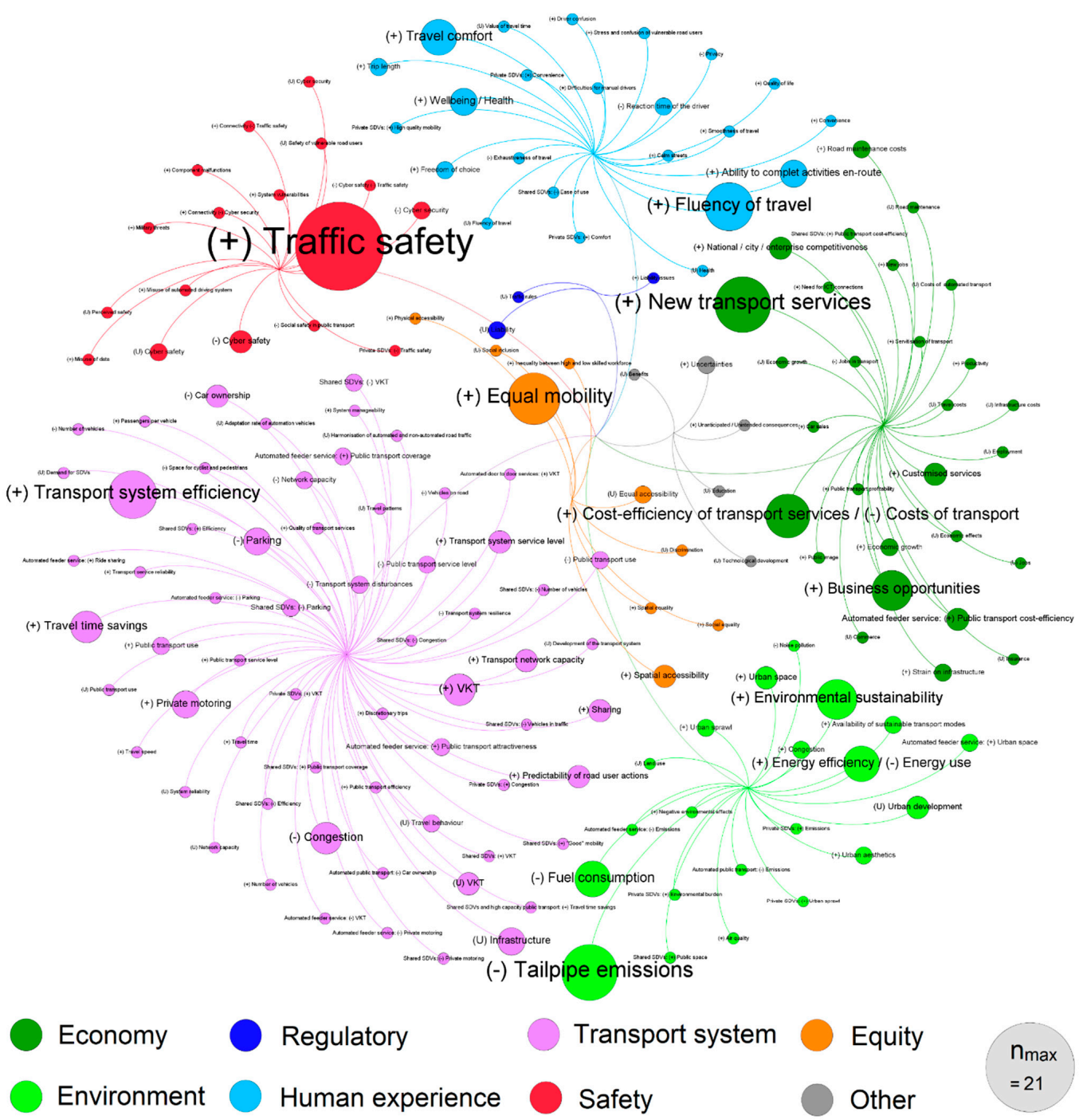

Figure 2. The anticipated implications identified from the analysed documents $(n=$ number of documents that mention an implication).

Some implications that are in principle identical but are worded differently are combined, but generally the variations of the same effect as well as closely linked implications 
are coded separately (e.g., decreased fuel consumption, increased energy efficiency, and increased environmental sustainability). The 14 most common anticipated implications are perceived as positive. Starting from increased traffic safety, mentioned in 21 documents, these include the prospect of new transport services (11), decreased tailpipe emissions (11), more equal mobility opportunities (11), enhanced fluency of travel (9), enhanced transport system efficiency (9), increased cost-efficiency of transport services (8), new business opportunities (8), enhanced environmental sustainability (8), more comfortable travel (8), decreased fuel consumption (6), enhanced energy efficiency (6), ease of congestion (5), and travel time savings (5). The most common negative effect, mentioned in five documents, is the increase in vehicle kilometres travelled (VKT). In total, five documents mention cyber threats: two discuss safety issues and two security issues, while one document addresses both aspects. Negative implications mentioned in two documents include increased private motoring, decreased public transport ridership, decreased public transport service level, increased congestion, increased trip length, increased urban sprawl, and several others. In total, $48.5 \%$ of the anticipated implications were positive, $26.6 \%$ negative, $23.7 \%$ uncertain, and $0.01 \%$ neutral, underlining the optimism towards the phenomenon. An implication was connected to a distinct way of implementing SDVs 35 times and the remaining 134 were attributed to automation in a very loosely defined context, such as "shared SDVs", or simply "transport automation" without defining the context in any way. However, in many of the latter cases, there seems to be an implicit assumption that transport automation will be primarily realised in the form of passenger cars, as illustrated by the quote at the end of the previous section.

Considering that the documents are produced by self-defined pro-automation actors, it is hardly surprising that the positive, negative, and uncertain implications are discussed unevenly. However, it is not only that the negatives and uncertainties are largely neglected, but when they are mentioned in the documents, they are often presented in a rather conspicuous way. Closer examination of the coded segments reveals that it is more common for the authors to confidently express causality between transport automation and positive effects, whereas negatives are far more often presented with ambiguous expressions or word choices reflecting uncertainty. Sometimes possible negative implications are not explicitly mentioned but are acknowledged as something that will be taken into account during the development. The following quotes exemplify the often stark contrast to the rhetoric of positive implications.

"The development of automation will create new and innovative alternatives for the customer to meet the need to travel." [68] (p. 4)

"The gradual increase in traffic automation will enhance and improve the availability of sustainable mobility services." [61] (p. 21)

"As development progresses, it must be ensured that data security and protection are built into the systems throughout their life cycle." [68] (p. 6)

"On the other hand, the reduction of jobs in the transport services sector, the growing insecurity of public transport services, and the decline in the number of public transport users are seen as potential challenges." [85] (p. 101)

The peremptory belief in the technology may stem from the fact that none of the documents truly connect the imaginary of automation into the complex realities of the Finnish mobility system or its needed sustainability transition. As mentioned, the implications are rarely connected to the implementations, and therefore the phenomenon remains a vaguely described ideal state to be reached that has no distinctive form. By using such a narrative, the authors extensively disregard the possibility of unanticipated consequences, the existence of multiple possible technological trajectories, as well as the apparent need for system-level intervention to manage the negative externalities of the passenger car. Instead, they focus mostly on positive effects, and where negative implications are mentioned, the emphasis is often placed on problems that may prevent or hinder the vehicles' market entry. Automated mobility, regardless of how it is realised, is expected to produce various positive 
implications as long as these barrier problems, such as cyber safety, security, liability, user acceptance, legislation, and the operational issues of the infant technology, are overcome. Although these aspects are indeed very important to bear in mind, the rhetoric underlines the narrowness of the discourse, the worrying lack of adequate foresight, and the omnipresent and vigorous technological determinisms surrounding SDVs [9,42,100,101].

\subsection{Sociocultural Practice}

Lastly, we come to the sociocultural practice. Having established our understanding of Finnish transport governance as a complex, under-researched subject and considering that transport automation is a society-wide phenomenon that is interconnected with numerous other emerging technologies and innumerable actors, we must note that our analysis of the sociocultural practices related to the automation imaginary in Finland is bound to be inexhaustive. That being said, our analysis is sufficient for providing a solid description of certain aspects of the Finnish governance culture and for using this description as grounds for critiquing the development process.

Serious deliberation about transport automation in Finnish transport governance began around 2012 when the former minister of transport, Merja Kyllönen, established the "New Transport Policy Club" that sought to "respond to the challenges of emissions, automatisation, and servitisation" [55] (p. 6). The automation discourse, most likely triggered by the seemingly accelerated technological progress and multiple car manufacturers revealing their plans for SDVs [102-105], found its way into public documents in the early and mid-2010s [77,90,93]. The early discussion revolved mostly around automatised privately owned vehicles, but the idea was quickly accompanied by the notion of sharing rides or vehicles, later dubbed as robot taxi services. In the following years, an ever-growing number of automated shuttle pilots in Finland and Europe established a new spearhead for transport automation development, namely one focused on public transport [106]. This newly found interest in transport automation was accompanied by several other considerable developments in the Finnish mobility regime that have played, and continue to play, a part in the development of the sociotechnical pathway.

The year 2014 marked the widespread introduction of the MaaS concept, whose connection to transport automation, we believe, should not be ignored in the Finnish context. A concept that has generated great interest as well as strife, MaaS has possibly received more public attention in recent years than any other idea or innovation in the Finnish transport regime. The explosion of interest was ignited by a master's thesis initiated by the City of Helsinki and ITS Finland, a public-private network originating from and financed by the MTC [107].

Modern conceptions of both MaaS and transport automation have started to seriously develop amidst a long-spanning discourse about the problematic nature of the automobility regime $[13,95]$. Finland, excluding several larger cities, is extremely car-dependant, and the debate regarding the mitigation of negative externalities of private motoring is constant and fervent. As suggested by previous research, due to this history of car dependance, Finnish transport governance has been tightly tied up with sustaining the status quo [53], and therefore the appeal of favouring technological substitution instead of social innovation as a solution is strong in the political discourse. Citing Dreamscapes of Modernity, Sadowski and Bendor [108] (p. 544) summarised that the success of sociotechnical imaginaries is dependant "on their fit with existing cultural norms and moral values, social structures and material infrastructure, political institutions and economic systems, and hopes and aspirations" and a process in which they are rendered through narratives as "intuitively recognizable, understandable, digestible, and relatable". MaaS is marketed with the promise of enhancing the environmental sustainability and efficiency of the transport system as well as freeing people from car ownership while maintaining at least the same level of "individual freedom" [52]. Similarly, as we have shown, the imagined forms of transport automation are expected to dissolve or ease multiple negative externalities of private motoring while maintaining or even enhancing the current mobility opportunities. Both promise to solve 
the undeniable problems of the transport system without making our current way of life unrecognisable. Possibly because of these shared expectations, the SDV and MaaS imaginaries have become increasingly intertwined and are often considered synergistic $[62,65,77,88]$.

The similarities of MaaS and automation discourses illustrate the wedlock of governance and the automobility system but also the disconnection between innovation-related policy and "general" transport policy. The documents that take a broader focus on transport system issues (e.g., $[60,66])$ show relatively extensive deliberation about various possible solutions. The range of examined means include, for example, the development of urban structure, taxation of fuels and vehicles, emissions trading, and road pricing, but relatively little emphasis is placed on phenomena such as transport automation and MaaS, even though the documents extend their projections as far as 2050. In contrast, many of the documents that primarily address transport automation depict the rapidly emerging selfdriving technologies as a fix to these problems but often fail to recognise local realities and the technologies' potential negative contribution. Consequently, the latter focus mostly on the simplistic idea of enablement instead of effective steering. Some authors even use extremely deterministic rhetoric, attributing a force-of-nature-like agency to automation by using expressions such as "preparing for the coming of automation" [62] (p. 37). Altogether, the documents tell an incoherent story about the governance regime that is at the same time conservatively pragmatic as well as naively wishful: major changes to the system are not envisioned, but at the same time, extensive technological substitution is expected to solve most of the system's problems. The cause of such representation can only be speculated in the boundaries of this study, but undoubtedly, a large number of constantly altering actors, the lack of communication as well as the dispersion (or lack) of roles, responsibilities, and expertise all play their part.

We must also recognise the institutional changes in the governance regime that were for the whole decade a continuous state of affairs. The purpose of the 2019 reform that resulted in the conception of the current agencies under the MTC was to "improve the administrative sector's ability to respond to changes in the operating environment", "develop and strengthen the strategic direction of the administrative sector", "obtain synergies", and also to "ensure and increase customer orientation and to take into account customer needs" [109]. The rationale was very similar to previous administrative changes in the early 2010s, which resulted in the conception of Trafi, as well as later organisational changes within the MTC [55] and recent legislative reforms. The 2017 act on transport services sought to accelerate digitalisation, increase the efficiency and quality of transport service production, and improve the competitiveness of transport service providers in home and global markets mostly by the means of deregulation [110]. In essence, the whole process of institutional evolution in the sector can be seen as a larger paradigm shift, where the actors have increasingly moved away from simply managing infrastructure to a more proactive open-market mindset: the transport sector is now seen as a previously unexplored frontier of innovation and economic opportunities on which the nation should seek to capitalise. In an even broader picture, the developments in the sector seem to align with the general shift from a cartel-like polity to more corporate-inspired ways of governance in Finland-a change that is often rationalised with rhetoric that situates Finland amid a global competition that creates almost a crisis-like struggle [111]. Indeed, the digitalisation of transport is presented as an urgent question of survival in the examined documents.

"The countries on the front line of digitalisation will also stand to benefit from it the most. Consequently, we should actively strive to be on the leading edge of this development if we wish to hold on to the welfare of our country. ... In order to promote the rapid adoption of new solutions, we must take risks and accept mistakes." [74] (p. 8-9)

This race mentality also extends to the innovation discourse embedded in the general discourse about transport automation. Causality is drawn between experimentation and numerous positive implications with no regard to various ways of organising experiments or the possible negative implications. The imagined development path relies on financing and facilitating ambitious experimentation, deregulation, and developing a progressive, interna- 
tionally attractive policy framework. Bold progressiveness, risk-taking, global recognition, and pursuit of the field leadership are portrayed as desirable and important, while missing out on the emerging opportunities is presented as a major threat. Public-private collaboration is stressed on many occasions, and the documents show that the governmental bodies view experiments and pilots as a pivotal part of the automation development in which they want to play an essential role. Despite this strong emphasis on experimentation and the several pilots conducted hitherto, a proper strategy is yet to be developed, and much like automation itself, experimentation seems to be regarded as inherently good. The previously mentioned techno-economic orientation of the regime is clearly visible here, as social aspects of testing, besides generating acceptance, are neglected throughout.

In general, very little has been said about involving the public in the development process. Instead, the authors discuss the development process mostly from the viewpoints of advancing a seemingly predetermined technological trajectory, creating acceptance and marketing the Finnish know-how and regulatory environment. Such a top-down approach to innovation is present, perhaps most notably, in the latest policy programme draft on transport automation. The document starts outlining the goals for Finnish transport automation from the principles of safety, efficiency, and sustainability and a claim that "it is important for people to be able to spend their time on activities other than driving as continuously as possible without having to monitor the traffic environment" [62] (p. 19). Subsequently, "Finland's goal is for this continuous non-driving time to be extended as quickly as possible" [62] (p. 19). The document then proceeds to present the preliminary actions for enabling automated driving on the Finnish road network. The focal point of the development is defined as the high-capacity road network, starting from the arterial road number three, and eventually, technology permitting, extending to all motorway sections over 100 kilometres and other high-service-level sections. All this is said without ever properly elaborating why is it important for people and what kind of implications such development might cause for the society as a whole.

\section{Conclusion}

\subsection{Discussion of Key Findings}

Clearly a sociotechnical imaginary, transport automation has been pursued through written discourse by multiple Finnish governmental bodies for almost a decade now. Our analysis reveals four distinct interpretations of the larger transport automation imaginary: private motoring, robot taxi service, public transport feeder service, and public transport in general. Private motoring is unquestionably the most widely deliberated one out of the four, followed by the robot taxi service. Interestingly, the public transport feeder service has received little interest in comparison, even though such services are being constantly tested in Finland. The possibility of introducing SDV technologies to other parts of the public transport system is also mentioned several times, but the details of these services are left almost completely undiscussed. Considering the strong emphasis placed on being on the frontlines of the development, it is rather surprising that the documents mostly reiterate vague, externally originated visions without seriously attempting to localise them into the Finnish transport system.

In comparison to previous research in other countries, the findings presented here show that the Finnish imaginary does, however, emphasise a very specific form of servitisation of automated transport: bundling of mobility services. The imaginaries of servitisation and automation developed simultaneously in the 2010s and are often considered synergistic. Even the earliest document in our sample, dating back to 2013, distinctly couples transport automation with the idea of service bundles that has later become synonymous with MaaS [77] (p. 8). Despite this relatively long history together, the two imaginaries are quite disconnected on the level of imagined implementations. Although they are often mentioned even in the same paragraphs, the authors have done little to decipher the complex implications that the coupling of bundled transport services and automation could 
create. Then again, even the contemplation of the automation imaginaries alone is severely deficient for numerous reasons, starting with the disconnection from local realities.

The rhetoric used to convey these visions is grounded enough to be seriously deliberated but vague enough to maintain interpretative flexibility, which in turn allows the imaginary to remain easily desirable and avoid conflicts. In addition, the automation imaginary as a whole is also highly deterministic. Intertwined with supranational visions of automated mobility and Finland's own car-dependant mobility culture, the most prevalent imagined implementations of SDVs are not viewed as a tool to disrupt the status quo but to make it sustainable. As said, out of the four identified variations, private motoring is unquestionably the strongest, and even certain depictions of the robot taxi service can be regarded as mere extensions of the automobility system, although the documents present contradicting views and only a few details. Moreover, the strong emphasis on private motoring is distinct even when the imagined implementations are not explicitly discussed. This leads us to perhaps the most severe shortcoming of the discourse- the failure to properly connect implications to the imagined implementations.

The desire to pursue automation is justified by a plethora of anticipated positive implications: enhanced traffic safety, new transport services and business opportunities, more sustainable and efficient transport system, more equal mobility opportunities, faster and more comfortable travel, and many more. In essence, transport automation is believed to fix the negative externalities of the current transport system while providing economic gain. However, the anticipated implications are, as said, rarely connected to the imagined implementations in the documents. Instead, they are often attributed simply to "transport automation". From a transport engineering point of view, suggesting that automation produces the same effects for all transport modes is incredibly misinformed. Yet, the narrative is even more troubling, as it leads to a shallow representation of automation as a feature to be added into the existing system based on private motoring while further cementing the status quo and neglecting the need for a systemic change.

It is also troubling that there is very little discussion about the relative importance of the potential implications, although it is clear that all possible implications are not equally important or desirable. The general promise of safety is strongly emphasised throughout the document sample, while the newest policy programme draft introduces human centricity as a central value in the development process [62]. Apart from these, close to no effort is made to determine on what terms automation should be advanced. Perhaps most notably, the documents avoid making any serious suggestions about the ways of addressing the threat of deeper lock-in to the system of automobility through automation. Adding the failure to sufficiently imagine negative outcomes and to consider the challenging process of co-creating a desirable sociotechnical trajectory to the list of deficiencies, we can only consider the high hopes presented in the discourse as naively optimistic. In terms of cultural and spatial (in)sensitivity, we conclude that the visions display a poor understanding of the complex realities of the Finnish mobility system, as transport automation is presented mostly as a matter of technological substitution, detached from people and institutions. These findings can be considered as further proof for several features of the Finnish governance culture already illustrated by the previous literature: the techno-economic orientation [51], the high emphasis on servitisation [52,55], and the agonising inertia to detach from the system of automobility [53].

The rhetoric of emerging opportunities is fused with a narrative that places Finland in a global competition, where a forerunner status is critical for reaping the benefits of the technology. Surviving in the global economy and maintaining the welfare of society is presented as a matter of keeping up with the rapid international development of technologies. Inevitably a question emerges whether the mentioned determinism coupled with this race mentality compromises reflective deliberation about truly desirable development paths. The lack of interest in creating meaningful citizen involvement is an alarming sign. Furthermore, there are questions about the overall quality of the knowledge generation process in the governance regime. Although we did not systematically analyse 
the references cited in the documents, even a glance through bibliographies reveals that the governmental bodies are not equipped with state-of-the-art academic research. Many of the mentioned benefits, such as traffic safety, transport system efficiency, more equal mobility opportunities, and positive environmental effects, have become increasingly questioned in the scientific literature (see, for example, $[9,25,28,35,36])$, but so far such healthy scepticism has not found its way into the Finnish governance discourse. As, according to Finnish law, the MTC's responsibilities include activities related to research, analysis, evaluation, and future anticipation, we consider such disregard for academia very troubling. Ultimately, the culture of enablement, the position that the MTC has declared for itself and its agencies [68] (p. 2), is not seamlessly compatible with its legal responsibilities, as it leads to a distorted starting point for the aforementioned activities.

Overall, our findings align well with the findings of previous research. Similarly to the UK and Germany [29,31], the Finnish stakeholders fail to acknowledge citizens as cocreators of an automated mobility future, although the importance of generating acceptance is stressed. Similarly to Norway, little emphasis is placed on actual implementations or the spatial and cultural realities, whereas economic gain and improvement of the transport sector are emphasised [22]. Previously identified features of the transport automation discourse, such as the dominant positive expectations, the race mentality, the driver problem fallacy, and the supposedly predetermined technological trajectories, are all part of the Finnish discourse as well $[28,36,44]$. The imagined implementations are also very similar to those that have for some years now circulated in the automation discourse, underlining the inherent supranationality of the phenomenon $[44,97,102,106]$. In terms of the whole development process, we can see similar threats related to lack of inclusivity, democracy, diversity, and transparency that have been reported elsewhere $[27,29,31,41]$. Thus, the lessons we offer for the Finnish governance regime in the next section could be interpreted also in different contexts.

Despite the above critique, we must acknowledge that the understanding of the phenomenon has increased in recent years. This is observable from some subtle changes in the discourse. Gratuitous optimism and a lack of critical perspective are continuous themes throughout the sample, but more recent documents by the MTC and Traficom, that have taken a broader perspective on transport system issues, have positioned transport automation as a tool among others for achieving certain goals-not as a magic bullet or an end itself $[60,85,88]$. Although so far contrasted with an absolute dearth of policies aiming for citizen involvement in the development of sociotechnical pathways, the MTC has also introduced the concept of human centricity into the discussion [62]. However, the most positive change has come from Traficom. The agency has taken concrete measures to advance equal accessibility in automated transport [87]. Moreover, the authors have acknowledged many of the possible contradictory implications and the danger of technological lock-ins $[85,88]$ even though the used rhetoric is sometimes regrettably deterministic. These documents are some of the first ones that show actual reflectivity about various possible implementations of transport automation while maintaining a relatively reasonable balance between technological optimism and uncertainty of the future. The documents about AI, published by the MEE, also show relatively extensive, culturally sensitive deliberation that acknowledges challenges relevant also to transport automation $[79,80,82]$. The AI discourse is at this time somewhat disconnected from transport automation, but the documents illustrate the possibility of advancing understanding through collaboration. Considering these changes in the discourse, it could be inferred that the governance regime is becoming more conscious of the complex nature of the automation phenomenon and its non-linear emergence.

\subsection{Governance Development Implications}

Based on the findings above, we could look for a plethora of reasons to justify why the governance regime has ended up having insufficiently inclusive, unreflective, and incomprehensive deliberation. These reasons certainly go back to several points already mentioned here and in previous literature, such as the problem of many hands, the insti- 
tutional void, the path-dependant illusion of determinism, misunderstanding of the role of the public, and the race mentality. In addition, one central factor might simply be the lack of understanding about transport automation and, more generally, the governance of emerging technologies. Whatever the reasons are, we can infer that if left unaddressed, such lack of awareness will bear perverse implications for Finnish society as a whole. Any further governance development should start from the MTC's legally set core functions of research, analysis, evaluation, and future anticipation.

Especially the last part about anticipation relates closely to the need for policy innovation, on the one hand, and changes in the governance culture, on the other hand. The needed policy innovation does not have to start from scratch. High-quality policy design can draw from a plethora of existing transport policies but also innovation policies [112,113]. Such innovation policy development could include various policy effectors and detectors related to, for example, data sharing, responsible piloting, indirect innovation, and innovation monitoring. This development process will also require careful policy packaging to evaluate the effectiveness and implementability of different policy combinations [114]. Among all these options, we consider the lack of reflection about public engagement policy especially troubling. While public involvement is by no means a panacea for successful governance, and at worst might serve as an artificial performance for legitimising predetermined courses of action, it is widely acknowledged that transparent governance activities with open deliberation are good methods for unveiling hidden problems in innovation, especially ones related to social heterogeneity [115-117]. Excluding the opportunity to comment on policy document drafts online, no open participation schemes have been carried out or included in any policy programmes or strategies so far. Thus, public engagement, which should enable deliberation about the various possible SDV implementations and their specific implications locally, is a clear direction for policy innovation. This deliberation must be inclusive by nature to accommodate the needs and desires of the various social groups and to achieve a higher level of knowledge and skill in governance. The opportunities for such policy innovation might relate to the ongoing development of national long-term transport and spatial plans.

Besides policy innovation, there is a larger question of governance culture change. The overly optimistic mentality about technology needs to change, especially because of the danger of the self-reinforcing loop of institutional void and unclear roles. Two critical preconceptions must be addressed. First, the emergence of technology must be understood as socially-constructed and not inevitable or inherently good [10]. Consequently, the emergence does not involve the adoption of a predetermined technology but a process of social (un)learning, where cultural values get solidified, developed, or destroyed as technology changes form and function over time. In addition, as emergence pertains to a redistribution of benefits and burdens, creating a sociotechnical pathway is also a question of distributive justice and not just total system efficiency [8]. Therefore, the core values, formed in collaboration with all relevant stakeholders, need to be clarified so that the relative importance of various possible implications is considered at all stages of implementation. This will reveal the inevitable value conflicts and prevent distorted view of emerging technologies as homogenous entities at an early enough stage to make better decisions about the long-term implications. In the case of transport automation, such an approach will undoubtedly bring forth currently neglected but already prevalent dilemmas related to, for example, providing personal convenience to some at the expense of those who cannot afford it and the larger societal good (see for example, [118]).

The second critical preconception to be addressed is the wide range of state roles concerning high-quality governance of sociotechnical transitions, as opposed to the false dichotomy of laissez-faire versus dictatorial control. Drawing from Borrás and Edler [119], and in contrast to the rhetoric used in the documents, the roles of national bodies could be further clarified as facilitators of specific dynamics, mitigators of undesired effects, and enablers of societal engagement. Further clarification of these roles goes hand in hand with understanding that governance is a pragmatic art of balancing between gatekeeping 
and laissez-faire actions over time. As such, high-quality governance is about intervening less but in a wiser way, as opposed to not intervening at all or trying to overcontrol the non-linear process of complex changes [21]. This pragmatic "muddling through", already advocated by Collingridge decades ago, must embrace contestation-oriented debate and the sense of discomfort that comes along with it, as these are essential for creativity and democracy in governance processes [54,120]. Only by addressing these critical preconceptions will the governance regime manage to balance its intent for being a positive changemaker with the intent of maintaining a high trust towards civil servants that Finnish society still has.

\subsection{Future Research Directions}

We believe that further cultural and spatial sensitisation of SDV-studies is necessary, as such an approach not only serves the academic purpose of knowledge generation but also opens a direct gateway to participate in the shaping of local sociotechnical trajectories. Continuing from existing examples [7,9], detailed comparative analysis is also needed, as underlining why certain SDV policies might be acceptable and effective in some places and not in others would serve a very practical purpose. In terms of our area of focus, Finland, there is a need for further analysis of transport governance. Unpacking the complex and layered constellation of actors, as already seen in the domain of urban planning [121], requires particular attention from academia. Again, this is not only important for knowledge generation but also to strengthen the democracy of Finnish transport policy processes.

We illustrated certain essential features of the transport automation imaginary in the Finnish governance context, but this analysis was not exhaustive. Better understanding is needed of the phenomena that are considered as synergistic, such as servitisation of transport, bundling of transport services, and home delivery and other logistics services. Understanding the conception of imaginaries and their interplay is crucial for understanding the ideologies that steer the governance regime. For example, the MaaS concept, which might hold a certain sentimental value for the Finnish governmental bodies due to its origin story, might be an interesting case to study governance culture in relation to deep meanings and emotions [122]. Overall, we hope that future research will build closer ties with sociology as well as philosophy of technology and innovation [123,124], as such conceptual depth is needed for developing reflective approaches towards emerging mobility technologies.

Supplementary Materials: The following are available online at https:/ / www.mdpi.com/article/10 .3390/su14031437/s1, Table S1: The anticipated implications identified from the analysed documents.

Author Contributions: Conceptualisation and writing, J.J.O. and M.N.M.; Data assembly, coding, data analysis, interpretative analysis, visualisation, J.J.O. All authors have read and agreed to the published version of the manuscript.

Funding: This research is funded by the FINEST Twins Center of Excellence (H2020 European Union funding for Research and Innovation grant 856602).

Data Availability Statement: The data presented in this study are available on request from the corresponding author.

Conflicts of Interest: The authors declare no conflict of interest.

\section{References}

1. Blyth, P.; Mladenovic, M.N.; Nardi, B.A.; Ekbia, H.R.; Su, N.M. Expanding the Design Horizon for Self-Driving Vehicles: Distributing Benefits and Burdens. IEEE Technol. Soc. Mag. 2016, 35, 44-49. [CrossRef]

2. Docherty, I.; Marsden, G.; Anable, J. The Governance of Smart Mobility. Transp. Res. Part Policy Pract. 2018, 115, 114-125. [CrossRef]

3. Milakis, D.; van Arem, B.; van Wee, B. Policy and Society Related Implications of Automated Driving: A Review of Literature and Directions for Future Research. J. Intell. Transp. Syst. 2017, 21, 324-348. [CrossRef]

4. Narayanan, S.; Chaniotakis, E.; Antoniou, C. Shared Autonomous Vehicle Services: A Comprehensive Review. Transp. Res. Part C Emerg. Technol. 2020, 111, 255-293. [CrossRef] 
5. Stead, D.; Vaddadi, B. Automated Vehicles and How They May Affect Urban Form: A Review of Recent Scenario Studies. Cities 2019, 92, 125-133. [CrossRef]

6. Stilgoe, J. Machine Learning, Social Learning and the Governance of Self-Driving Cars. Soc. Stud. Sci. 2018, 48, 25-56. [CrossRef]

7. Taeihagh, A.; Lim, H.S.M. Governing Autonomous Vehicles: Emerging Responses for Safety, Liability, Privacy, Cybersecurity, and Industry Risks. Transp. Rev. 2019, 39, 103-128. [CrossRef]

8. Mladenović, M. How Should We Drive Self-Driving Vehicles? Anticipation and Collective Imagination in Planning Mobility Futures. In The Governance of Smart Transportation Systems: Towards New Organizational Structures for the Development of Shared, Automated, Electric and Integrated Mobility; Finger, M., Audouin, M., Eds.; Springer: Cham, Switzerland, 2019; pp. 103-122; ISBN 978-3-319-96526-0.

9. Mladenović, M.; Stead, D.; Milakis, D.; Pangbourne, K.; Givoni, M. Governance Cultures and Socio-Technical Imaginaries of Self-Driving Technology: Comparative Analysis of Finland, UK and Germany. In Advances in Transport Policy and Planning; Academic Press: Cambridge, MA, USA, 2020; pp. 235-262. [CrossRef]

10. Winner, L. Do Artifacts Have Politics? Daedalus 1980, 109, 121-136. Available online: https://www.jstor.org/stable/20024652 (accessed on 29 October 2021).

11. Genus, A.; Stirling, A. Collingridge and the Dilemma of Control: Towards Responsible and Accountable Innovation. Res. Policy 2018, 47, 61-69. [CrossRef]

12. Jasanoff, S.; Kim, S.-H. Containing the Atom: Sociotechnical Imaginaries and Nuclear Power in the United States and South Korea. Minerva 2009, 47, 119. [CrossRef]

13. Norton, P.D. Fighting Traffic: The Dawn of the Motor Age in the American City; MIT Press: Cambridge, MA, USA; London, UK, 2011; ISBN 978-0-262-14100-0.

14. Paulsson, A.; Hylander, J.; Hrelja, R. One for All, or All for Oneself? Governance Cultures in Regional Public Transport Planning. Eur. Plan. Stud. 2017, 25, 2293-2308. [CrossRef]

15. Booth, P. Planning and the Culture of Governance: Local Institutions and Reform in France. Eur. Plan. Stud. 2009, 17, 677-695. [CrossRef]

16. Reimer, M.; Blotevogel, H.H. Comparing Spatial Planning Practice in Europe: A Plea for Cultural Sensitization. Plan. Pract. Res. 2012, 27, 7-24. [CrossRef]

17. Stead, D. Policy Preferences and the Diversity of Instrument Choice for Mitigating Climate Change Impacts in the Transport Sector. J. Environ. Plan. Manag. 2018, 61, 2445-2467. [CrossRef]

18. Thompson, D.F. Moral Responsibility of Public Officials: The Problem of Many Hands. Am. Polit. Sci. Rev. 1980, 74, 905-916. [CrossRef]

19. Hajer, M. Policy without Polity? Policy Analysis and the Institutional Void. Policy Sci. 2003, 36, 175-195. [CrossRef]

20. Howlett, M. Governance Modes, Policy Regimes and Operational Plans: A Multi-Level Nested Model of Policy Instrument Choice and Policy Design. Policy Sci. 2009, 42, 73-89. [CrossRef]

21. Colander, D.; Kupers, R. Complexity and the Art of Public Policy: Solving Society's Problems from the Bottom Up; Princeton University Press: Princeton, NJ, USA; Oxford, UK, 2014; ISBN 978-1-4008-5013-6.

22. Haugland, B.T. Changing Oil: Self-Driving Vehicles and the Norwegian State. Humanit. Soc. Sci. Commun. 2020, 7, 180. [CrossRef]

23. Hansson, L. Regulatory Governance in Emerging Technologies: The Case of Autonomous Vehicles in Sweden and Norway. Res. Transp. Econ. 2020, 83, 100967. [CrossRef]

24. Marsden, G.; Reardon, L. Questions of Governance: Rethinking the Study of Transportation Policy. Transp. Res. Part Policy Pract. 2017, 101, 238-251. [CrossRef]

25. Papa, E.; Ferreira, A. Sustainable Accessibility and the Implementation of Automated Vehicles: Identifying Critical Decisions. Urban Sci. 2018, 2, 5. [CrossRef]

26. Hopkins, D.; Schwanen, T. Experimentation with Vehicle Automation. In Transitions in Energy Efficiency and Demand; Jenkins, K., Hopkins, D., Eds.; Routledge: Abingdon, UK, 2018; pp. 72-93. ISBN 978-0-367-66328-5.

27. Stilgoe, J. Who's Driving Innovation? New Technologies and the Collaborative State; Springer Nature: Cham, Switzerland, 2019; ISBN 978-3-030-32320-2.

28. Braun, R.; Randell, R. Futuramas of the Present: The "Driver Problem" in the Autonomous Vehicle Sociotechnical Imaginary. Humanit. Soc. Sci. Commun. 2020, 7, 163. [CrossRef]

29. Graf, A.; Sonnberger, M. Responsibility, Rationality, and Acceptance: How Future Users of Autonomous Driving Are Constructed in Stakeholders' Sociotechnical Imaginaries. Public Underst. Sci. 2020, 29, 61-75. [CrossRef] [PubMed]

30. Martin, R. AV Futures or Futures with AVs? Bridging Sociotechnical Imaginaries and a Multi-Level Perspective of Autonomous Vehicle Visualisations in Praxis. Humanit. Soc. Sci. Commun. 2021, 8, 68. [CrossRef]

31. Tennant, C.; Howard, S.; Stares, S. Building the UK Vision of a Driverless Future: A Parliamentary Inquiry Case Study. Humanit. Soc. Sci. Commun. 2021, 8, 204. [CrossRef]

32. Finnish Transport Agency. Finnish National Travel Survey. Available online: https://www.traficom.fi/en/news/publications/ finnish-national-travel-survey (accessed on 26 November 2021).

33. Grindsted, T.S.; Christensen, T.H.; Freudendal-Pedersen, M.; Friis, F.; Hartmann-Petersen, K. The Urban Governance of Autonomous Vehicles-In Love with AVs or Critical Sustainability Risks to Future Mobility Transitions. Cities 2021, 120 , 103504. [CrossRef] 
34. Chen, S.-Y.; Kuo, H.-Y.; Lee, C. Preparing Society for Automated Vehicles: Perceptions of the Importance and Urgency of Emerging Issues of Governance, Regulations, and Wider Impacts. Sustainability 2020, 12, 7844. [CrossRef]

35. Cohen, T.; Cavoli, C. Automated Vehicles: Exploring Possible Consequences of Government (Non)Intervention for Congestion and Accessibility. Transp. Rev. 2019, 39, 129-151. [CrossRef]

36. Cohen, T.; Stilgoe, J.; Cavoli, C. Reframing the Governance of Automotive Automation: Insights from UK Stakeholder Workshops. J. Responsible Innov. 2018, 5, 257-279. [CrossRef]

37. Fagnant, D.J.; Kockelman, K. Preparing a Nation for Autonomous Vehicles: Opportunities, Barriers and Policy Recommendations. Transp. Res. Part Policy Pract. 2015, 77, 167-181. [CrossRef]

38. Freemark, Y.; Hudson, A.; Zhao, J. Are Cities Prepared for Autonomous Vehicles? J. Am. Plan. Assoc. 2019, 85, 133-151. [CrossRef]

39. Guerra, E. Planning for Cars That Drive Themselves: Metropolitan Planning Organizations, Regional Transportation Plans, and Autonomous Vehicles. J. Plan. Educ. Res. 2016, 36, 210-224. [CrossRef]

40. Hess, D.J. Incumbent-Led Transitions and Civil Society: Autonomous Vehicle Policy and Consumer Organizations in the United States. Technol. Forecast. Soc. Change 2020, 151, 119825. [CrossRef]

41. Hopkins, D.; Schwanen, T. Automated Mobility Transitions: Governing Processes in the UK. Sustainability 2018, 10, 956. [CrossRef]

42. Legacy, C.; Ashmore, D.; Scheurer, J.; Stone, J.; Curtis, C. Planning the Driverless City. Transp. Rev. 2019, 39, 84-102. [CrossRef]

43. Kröger, W. Automated Vehicle Driving: Background and Deduction of Governance Needs. J. Risk Res. 2021, 24, 14-27. [CrossRef]

44. Hopkins, D.; Schwanen, T. Talking about Automated Vehicles: What Do Levels of Automation Do? Technol. Soc. 2021, 64, 101488. [CrossRef]

45. Bache, I.; Bartle, I.; Flinders, M. Multi-Level Governance. In Handbook on Theories of Governance; Ansell, C., Torfing, J., Eds.; Edward Elgar Publishing: Northampton, MA, USA, 2016; pp. 486-498. ISBN 978-1-78254-849-2.

46. Latour, B. On Actor-Network Theory: A Few Clarifications. Soz. Welt 1996, 47, 369-381. Available online: https://www.jstor.org/ stable/40878163 (accessed on 27 October 2021).

47. Olsson, N.O.E.; Nyström, J.; Pyddoke, R. Governance Regimes for Large Transport Infrastructure Investment Projects: Comparative Analysis of Norway and Sweden. Case Stud. Transp. Policy 2019, 7, 837-848. [CrossRef]

48. Finlex Ajantasainen Lainsäädäntö: Liikenne-ja Viestintäministeriön Työjärjestys 1267/2015. Available online: https:/ finlex.fi/fi/ laki/ajantasa/2015/20151267 (accessed on 27 October 2021).

49. Tuominen, A.; Himanen, V. Assessing the Interaction between Transport Policy Targets and Policy Implementation-A Finnish Case Study. Transp. Policy 2007, 14, 388-398. [CrossRef]

50. Kivimaa, P.; Virkamäki, V. Policy Mixes, Policy Interplay and Low Carbon Transitions: The Case of Passenger Transport in Finland. Environ. Policy Gov. 2014, 24, 28-41. [CrossRef]

51. Leviäkangas, P. Digitalisation of Finland's Transport Sector. Technol. Soc. 2016, 47, 1-15. [CrossRef]

52. Pangbourne, K.; Mladenović, M.N.; Stead, D.; Milakis, D. Questioning Mobility as a Service: Unanticipated Implications for Society and Governance. Transp. Res. Part Policy Pract. 2020, 131, 35-49. [CrossRef]

53. Upham, P.; Kivimaa, P.; Virkamäki, V. Path Dependence and Technological Expectations in Transport Policy: The Case of Finland and the UK. J. Transp. Geogr. 2013, 32, 12-22. [CrossRef]

54. Mladenović, M.N.; Haavisto, N. Interpretative Flexibility and Conflicts in the Emergence of Mobility as a Service: Finnish Public Sector Actor Perspectives. Case Stud. Transp. Policy 2021, 9, 851-859. [CrossRef]

55. Kivimaa, P.; Rogge, K.S. Interplay of Policy Experimentation and Institutional Change in Sustainability Transitions: The Case of Mobility as a Service in Finland. Res. Policy 2022, 51, 104412. [CrossRef]

56. Karlsson, I.C.M.; Mukhtar-Landgren, D.; Smith, G.; Koglin, T.; Kronsell, A.; Lund, E.; Sarasini, S.; Sochor, J. Development and Implementation of Mobility-as-a-Service-A Qualitative Study of Barriers and Enabling Factors. Transp. Res. Part A Policy Pract. 2020, 131, 283-295. [CrossRef]

57. Jasanoff, S.; Kim, S.-H. Dreamscapes of Modernity: Sociotechnical Imaginaries and the Fabrication of Power; University of Chicago Press: Chicago, IL, USA, 2015; ISBN 978-0-226-27666-3.

58. Pinch, T.J.; Bijker, W.E. The Social Construction of Facts and Artefacts: Or How the Sociology of Science and the Sociology of Technology Might Benefit Each Other. Soc. Stud. Sci. 1984, 14, 399-441. [CrossRef]

59. Fairclough, N. Critical Discourse Analysis: The Critical Study of Language; Longman Publishing: New York, NY, USA, 1995; ISBN 0-582-21980-9.

60. Ministry of Transport and Communications; Andersson, A.; Jääskeläinen, S.; Saarinen, N.; Mänttäri, J.; Hokkanen, E. Road Map for Fossil-Free Transport-Working Group Final Report. Available online: https://julkaisut.valtioneuvosto.fi/handle/10024/162516 (accessed on 29 October 2021).

61. Ministry of Transport and Communications. Road Map for Fossil-Free Transport-Draft of the Decision in Principle by the Finnish Government to Reduce Greenhouse Gas Emissions of Homeland Transport. Available online: https:/ /www.lausuntopalvelu.fi/ FI/Proposal/Participation?proposalId=c73d3be8-1bab-4878-9807-799f50e81d04 (accessed on 29 October 2021).

62. Ministry of Transport and Communications. Draft of the Transport Automation Legislation and Key Policy Measure Plan. Available online: https:/ / www.lausuntopalvelu.fi/FI/Proposal/Participation?proposalId=673ce01a-af6d-4da0-a2f6-a3b7519ae6 $8 b$ (accessed on 29 October 2021).

63. Ministry of Transport and Communications. National Transport System Plan Impact Assessment Programme. Available online: https://julkaisut.valtioneuvosto.fi/handle/10024/161890 (accessed on 29 October 2021). 
64. Ministry of Transport and Communications. Well-Being and Sustainable Growth with Well-Functioning Networks, Services and Information-Futures Review by the Ministry of Transport and Communications. Available online: https://julkaisut. valtioneuvosto.fi/handle/10024/160924 (accessed on 29 October 2021).

65. Ministry of Transport and Communications; Särkijärvi, J.; Jääskeläinen, S.; Lohko-Soner, K. Carbon-Free Transport by 2045Paths to an Emission-Free Future, Interim Report by the Transport Climate Policy Working Group. Available online: https: / /julkaisut.valtioneuvosto.fi/handle/10024/161029 (accessed on 29 October 2021).

66. Ministry of Transport and Communications; Särkijärvi, J.; Jääskeläinen, S.; Lohko-Soner, K. Action Programme for Carbon-Free Transport 2045 Final Report by the Transport Climate Policy Working Group. Available online: https://julkaisut.valtioneuvosto. fi/handle/10024/161210 (accessed on 29 October 2021).

67. Ministry of Transport and Communications; Laakso, J.; Vesanto, A.; Ritari, J. Analysis of the Data and Development Needs of Automated Driving. Available online: https://julkaisut.valtioneuvosto.fi/handle/10024/160503 (accessed on 29 October 2021).

68. Ministry of Transport and Communications; Arola, T.; Antikainen, P. A Roadmap for Developing Automation and Robotics in Transport Sector 2017-2019. Available online: https:/ /julkaisut.valtioneuvosto.fi/handle/10024/79868 (accessed on 29 October 2021).

69. Ministry of Transport and Communications; Vesanen-Nikitin, I.; Åkermarck, M. Making Digital Transport and Communication Services Accessible. Action Programme 2017-2021. Available online: https://julkaisut.valtioneuvosto.fi/handle/10024/79917 (accessed on 29 October 2021).

70. Ministry of Transport and Communications; Aho, E.; Lyly, L.; Mero, I. Transport and Communications Architecture 2030 and 2050. Available online: https://julkaisut.valtioneuvosto.fi/handle/10024/79795 (accessed on 29 October 2021).

71. Ministry of Transport and Communications. Better Transport Infrastructure-More Efficient Transport Services. Report on the Business Development of the Transport Network: Transport Network Company. Available online: https://julkaisut. valtioneuvosto.fi/handle/10024/79176 (accessed on 29 October 2021).

72. Ministry of Transport and Communications. Background Reports on Robotics. Available online: https://julkaisut.valtioneuvosto. fi/handle/10024/78250 (accessed on 29 October 2021).

73. Ministry of Transport and Communications. Traffic Safety from Knowledge-Decision in Principle by the Finnish Government to Enhance Road Safety. Available online: https://julkaisut.valtioneuvosto.fi/handle/10024/79137 (accessed on 29 October 2021).

74. Ministry of Transport and Communications. Robots on Land, in Water and in the Air-Promoting Intelligent Automation in Transport Services. Available online: https://julkaisut.valtioneuvosto.fi/handle/10024/78361 (accessed on 29 October 2021).

75. Ministry of Transport and Communications. Our Road to the Future. Futures Review on Road Safety. Available online: https:/ /julkaisut.valtioneuvosto.fi/handle/10024/77861 (accessed on 29 October 2021).

76. Ministry of Transport and Communications. Smart City-Overview of Smart Services and Possibilities. Available online: https:/ /julkaisut.valtioneuvosto.fi/handle/10024/77892 (accessed on 29 October 2021).

77. Ministry of Transport and Communications. Fair and Intelligent Transport-Working Group Final Report. Available online: https:/ /julkaisut.valtioneuvosto.fi/handle/10024/77940 (accessed on 29 October 2021).

78. Ministry of Economic Affairs and Employment; Metsäranta, H.; Rannikko, H.; Toivanen, M.; Rausmaa, S.; Wennberg, M. Transport Sector Indicators and Situational Picture. Proposals for Growth Programme Assessment and for Monitoring the Sector's Development. Available online: https:/ /julkaisut.valtioneuvosto.fi/handle/10024/162316 (accessed on 29 October 2021).

79. Ministry of Economic Affairs and Employment. Leading the Way into the Age of Artificial Intelligence-Final Report of Finland's Artificial Intelligence Programme 2019. Available online: https:/ julkaisut.valtioneuvosto.fi/handle/10024/161447 (accessed on 29 October 2021).

80. Ministry of Economic Affairs and Employment; Koski, O.; Husso, K. Work in the Age of Artificial Intelligence: Four Perspectives on the Economy, Employment, Skills and Ethics. Available online: https://julkaisut.valtioneuvosto.fi/handle/10024/160931 (accessed on 29 October 2021).

81. Ministry of Economic Affairs and Employment; Lintilä, M.; Berner, A.; Leppä, J.; Tiilikainen, K.; Mäkelä, J.; Vapaavuori, J.; Laajala, P.; Lyly, L.; Arve, M.; et al. National Growth Programme for the Transport Sector 2018-022. Available online: https:/ /julkaisut.valtioneuvosto.fi/handle/10024/160721 (accessed on 29 October 2021).

82. Ministry of Economic Affairs and Employment. Finland's Age of Artifical Intelligence-Turning Finland into a Leading Country in the Application of Artifical Intelligence. Available online: https://julkaisut.valtioneuvosto.fi/handle/10024/80849 (accessed on 29 October 2021).

83. Ministry of Economic Affairs and Employment. Government Report on the National Energy and Climate Strategy for 2030. Available online: https://julkaisut.valtioneuvosto.fi/handle/10024/79247 (accessed on 29 October 2021).

84. Traficom; Penttinen, M.; Luoma, J. From Driver Support Systems to Automation. Available online: https://www.traficom.fi/sites/ default/files/media/file/Kuljettajan\%20tukij\%C3\%A4rjestelmist\%C3\%A4\%20automaatioon\%20Traficom\%20.pdf (accessed on 29 October 2021).

85. Traficom. The Current State of the Transport System and the Changes in Its Operating Environment. Available online: https://www.traficom.fi/sites/default/files/media/publication/Liikennej\%C3\%A4rjestelm\%C3\%A4n \%20nykytila\%20ja\%20 toimintaymp $\%$ C3\%A4rist $\%$ C3\%B6n\%20muutokset_raportti.pdf (accessed on 29 October 2021). 
86. Traficom; Penttinen, M.; Luoma, J.; Mesimäki, J. How Safe Must Automated Cars Be? Available online: https://www.traficom. fi/sites/default/files/media/publication/Kuinka_turvallisia_automaattiautojen_Traficom_2_2019.pdf (accessed on 29 October 2021).

87. Traficom; Sakari, S.; Terhi, T.; Atte, M.; Azra, T.; Petteri, A. Preliminary Report on the Accessibility of Automated Road Vehicles and Transport Services. Available online: https://www.traficom.fi/sites/default/files/media/publication/Traficom\% 20tutkimusraportti_24_2019_AUTOESTE_101219.pdf (accessed on 29 October 2021).

88. Traficom; Kulmala, R.; Jääskeläinen, J.; Pakarinen, S. The Impact of Automated Transport on the Role, Operations and Costs of Road Operators and Authorities in Finland. Available online: https://www.traficom.fi/sites/default/files/media/publication/ EU_EIP_Impact_of_Automated_Transport_Finland_Traficom_6_2019.pdf (accessed on 29 October 2021).

89. Trafi. The State of Transport 2030. Available online: https://arkisto.trafi.fi/filebank/a/1476367622/f61da0cdfc2bf85e8df89c0de1 9d5587/22797-Trafi_Liikenteen_Tila_2030.pdf (accessed on 29 October 2021).

90. Trafi; Innamaa, S.; Kanner, H.; Rämä, P.; Virtanen, A. The Effects of Increased Automation in Road Transport. Available online: https:/ / arkisto.trafi.fi/filebank/a/1461576365/fdb4c6b311fb1da01cf40bdf8fd33b5c/20473-Trafi_tutkimuksia_01-2015_ __Automaattiajaminen.pdf (accessed on 29 October 2021).

91. The Commitee for the Future; Linturi, R.; Kuusi, O. Societal Transformation 2018-2037: 100 Anticipated Radical Technologies, 20 Regimes, Case Finland. Available online: https:/ /www.eduskunta.fi:443/FI/valiokunnat/tulevaisuusvaliokunta/julkaisut/ Sivut/societal-transformation-2018-2037.aspx (accessed on 29 October 2021).

92. Finnish Transport Agency; Lumiaho, A.; Malin, F. Road Transport Automation Road Map and Action Plan 2016-2020. Available online: https://julkaisut.vayla.fi/pdf8/lts_2016-19_tieliikenteen_automatisoinnin_web.pdf (accessed on 29 October 2021).

93. Temmes, A.; Virkamäki, V.; Kivimaa, P.; Upham, P.; Hildén, M.; Lovio, R. Innovation Policy Options for Sustainability Transitions in Finnish Transport. Tekes Rev. 2014, 306, 5-53.

94. Berkhout, F. Normative Expectations in Systems Innovation. Technol. Anal. Strateg. Manag. 2006, 18, 299-311. [CrossRef]

95. Urry, J. The 'System' of Automobility. Theory Cult. Soc. 2004, 21, 25-39. [CrossRef]

96. Geels, F.W. A Socio-Technical Analysis of Low-Carbon Transitions: Introducing the Multi-Level Perspective into Transport Studies. J. Transp. Geogr. 2012, 24, 471-482. [CrossRef]

97. Bischoff, J.; Maciejewski, M. Autonomous Taxicabs in Berlin-a Spatiotemporal Analysis of Service Performance. Transp. Res. Procedia 2016, 19, 176-186. [CrossRef]

98. Fagnant, D.J.; Kockelman, K.M. Dynamic Ride-Sharing and Fleet Sizing for a System of Shared Autonomous Vehicles in Austin, Texas. Transportation 2018, 45, 143-158. [CrossRef]

99. Lu, M.; Taiebat, M.; Xu, M.; Hsu, S.-C. Multiagent Spatial Simulation of Autonomous Taxis for Urban Commute: Travel Economics and Environmental Impacts. J. Urban Plan. Dev. 2018, 144, 04018033. [CrossRef]

100. Currie, G. Lies, Damned Lies, AVs, Shared Mobility, and Urban Transit Futures. J. Public Transp. 2018, 21, 19-30. [CrossRef]

101. Wyatt, S. Technological Determinism Is Dead; Long Live Technological Determinism. In The Handbook of Science and Technology Studies; Hackett, E.J., Amsterdamska, O., Lynch, M., Wajcman, J., Eds.; MIT Press: Cambridge, MA, USA; London, UK, 2008; Volume 3, pp. 165-180.

102. Beiker, S. History and Status of Automated Driving in the United States. In Road Vehicle Automation; Meyer, G., Beiker, S., Eds.; Springer International Publishing: Cham, Switzerland, 2014; pp. 61-70. ISBN 978-3-319-05990-7.

103. Meyer, G.; Deix, S. Research and Innovation for Automated Driving in Germany and Europe. In Road Vehicle Auto-Mation; Meyer, G., Beiker, S., Eds.; Springer International Publishing: Cham, Switzerland, 2014; pp. 71-81. ISBN 978-3-319-05990-7.

104. Pendleton, S.D.; Andersen, H.; Du, X.; Shen, X.; Meghjani, M.; Eng, Y.H.; Rus, D.; Ang, M.H. Perception, Planning, Control, and Coordination for Autonomous Vehicles. Machines 2017, 5, 6. [CrossRef]

105. Anderson, J.M.; Kalra, N.; Stanley, K.D.; Sorensen, P.; Samaras, C.; Oluwatola, O.A. Brief History and Current State of Autonomous Vehicles. In Autonomous Vehicle Technology: A Guide for Policymakers; RAND Corporation: Santa Monica, CA, USA, 2014; pp. 55-74. ISBN 978-0-8330-8398-2.

106. Ainsalu, J.; Arffman, V.; Bellone, M.; Ellner, M.; Haapamäki, T.; Haavisto, N.; Josefson, E.; Ismailogullari, A.; Lee, B.; Madland, O. State of the Art of Automated Buses. Sustainability 2018, 10, 3118. [CrossRef]

107. Heikkilä, S. Mobility as a Service-A Proposal for Action for the Public Administration, Case Helsinki. 2014. Available online: http:/ / urn.fi/URN:NBN:fi:aalto-201405221895 (accessed on 29 October 2021).

108. Sadowski, J.; Bendor, R. Selling Smartness: Corporate Narratives and the Smart City as a Sociotechnical Imaginary. Sci. Technol. Hum. Values 2019, 44, 540-563. [CrossRef]

109. Ministry of Transport and Communications. Eduskunta Hyväksyi Liikenne-ja Viestintäministeriön Hallinnonalan Uudistuksen. Available online: https:/ / www.lvm.fi/-/eduskunta-hyvaksyi-liikenne-ja-viestintaministerion-hallinnonalan-uudistuksen-98 6542 (accessed on 28 October 2021).

110. Finlex Ajantasainen Lainsäädäntö: Laki Liikenteen Palveluista 320/2017. Available online: https://www.finlex.fi/fi/laki/ ajantasa/2017/20170320 (accessed on 28 October 2021).

111. Ahlqvist, T.; Moisio, S. Neoliberalisation in a Nordic State: From Cartel Polity towards a Corporate Polity in Finland. New Polit. Econ. 2014, 19, 21-55. [CrossRef] 
112. Mladenović, M.N.; Stead, D. Chapter 5-Emerging Mobility Technologies and Transitions of Urban Space Allocation in a Nordic Governance Context. In Urban Form and Accessibility; Mulley, C., Nelson, J.D., Eds.; Elsevier: Amsterdam, The Netherlands, 2021; pp. 63-82. ISBN 978-0-12-819822-3.

113. Mladenović, M.N.; Haapamäki, T.; Koste, O.-W.; Mäkinen, S.; Neuvonen, A.; Weckström, C. Liikkumisen Kestävien Palvelumarkkinoiden Ohjauskeinot (LIIKE-PALO). Available online: https://julkaisut.valtioneuvosto.fi/handle/10024/163427 (accessed on 28 November 2021).

114. Howlett, M.; Rayner, J. Patching vs Packaging in Policy Formulation: Assessing Policy Portfolio Design. Polit. Gov. 2013, 1, 170-182. [CrossRef]

115. Stilgoe, J.; Owen, R.; Macnaghten, P. Developing a Framework for Responsible Innovation. Res. Policy 2013, 42, 1568-1580. [CrossRef]

116. Felt, U.; Fochler, M. Machineries for Making Publics: Inscribing and De-Scribing Publics in Public Engagement. Minerva 2010, 48, 219-238. [CrossRef]

117. Irwin, A.; Jensen, T.E.; Jones, K.E. The Good, the Bad and the Perfect: Criticizing Engagement Practice. Soc. Stud. Sci. 2013, 43, 118-135. [CrossRef]

118. Schwanen, T. Urban Transport and Wellbeing: A Critical Analysis. In Transport in Human Scale Cities; Edward El-gar Publishing Limited: Cheltenham, UK, 2021; pp. 14-26. ISBN 978-1-80037-050-0.

119. Borrás, S.; Edler, J. The Roles of the State in the Governance of Socio-Technical Systems' Transformation. Res. Policy 2020, 49, 103971. [CrossRef]

120. Valkenburg, G. Consensus or Contestation: Reflections on Governance of Innovation in a Context of Heterogene-ous Knowledges. Sci. Technol. Soc. 2020, 25, 341-356. [CrossRef]

121. Eräranta, S.; Mladenović, M.N. Networked Dynamics of Knowledge Integration in Strategic Spatial Planning Pro-cesses: A Social Network Approach. Reg. Stud. 2021, 55, 870-882. [CrossRef]

122. Vuori, T.O.; Huy, Q.N. Distributed Attention and Shared Emotions in the Innovation Process: How Nokia Lost the Smartphone Battle. Adm. Sci. Q. 2016, 61, 9-51. [CrossRef]

123. Mladenović, M.N.; Lehtinen, S.; Soh, E.; Martens, K. Emerging Urban Mobility Technologies through the Lens of Everyday Urban Aesthetics: Case of Self-Driving Vehicle. Essays Philos. 2019, 20, 146-170. [CrossRef]

124. Cohen, T.; Stilgoe, J.; Stares, S.; Akyelken, N.; Cavoli, C.; Day, J.; Dickinson, J.; Fors, V.; Hopkins, D.; Lyons, G.; et al. A Constructive Role for Social Science in the Development of Automated Vehicles. Transp. Res. Interdiscip. Perspect. 2020, 6, 100133. [CrossRef] 